\title{
Do expectations matter? The Great Moderation revisited
}

\author{
Fabio Canova, U Bern, ICREA-UPF, AMeN and CEPR \\ Luca Gambetti, Universitat Autonoma de Barcelona and ReCENT *
}

This version, April 2008

\begin{abstract}
We examine the role of expectations in the Great Moderation episode. We derive theoretical restrictions in a New-Keynesian model and test them using measures of expectations obtained from survey data, the Greenbook and bond markets. Expectations explain the dynamics of inflation and of interest rates but their importance is roughly unchanged over time. Systems with and without expectations display similar reduced form characteristics. Including or excluding expectations hardly changes the economic explanation of the Great Moderation. Results are robust to changes in the structure of the empirical model.
\end{abstract}

JEL classification: C11, E12, E32, E62

Key Words: Indeterminacy, Expectations, Term structure, Structural VARs, Sunspot shocks.

\footnotetext{
${ }^{*}$ We thank Luca Benati for sharing codes with us, Carlo Favero for providing us with zero coupon term structure data, Lucrezia Reichlin, Ken West, John Williams, Russell Cooper, Dale Henderson, Andrew Levin and the participant of several seminars and conferences for comments and suggestions. Both authors acknowledge the financial support of the Spanish Ministry of Education through the grant SEJ-2004-21682-E. Canova also acknowledges financial support from CREI.
} 


\section{Introduction}

Many authors have examined the "Great Moderation" episode in the US (see Clarida, et. al. (2000), Blanchard and Simon (2001), Cogley and Sargent (2001) (2005), Stock and Watson (2002), Gambetti et. al. (2005), Gordon (2005) Primiceri (2005), Arias, et. al. (2006), Sims and Zha (2006) among others) and its international features are currently investigated (see Stock and Watson (2004), Benati and Mumtaz (2006) or Canova, et. al. (2007)). Most analyses agree on the observation that the volatility and the persistence of output and inflation declined since the late 1970s but explanations differ. The literature is mainly divided into two fronts - those who support the "bad policy" hypothesis (failure of the Fed to appropriately respond to inflation) and those who lean toward the "bad luck" hypothesis (shocks are drawn from a time varying distribution) - with a few authors claiming that changes in the private sector (see e.g. McConnell and Perez Quiroz (2001), Canova (2005), Campbell and Herkovitz (2006), Jerman and Quadrini (2006)) or reduced activism combined with decreased misperceptions (Orphanides (2004), Orphanides and Williams (2005)) may be responsible for the phenomenon. The division appears to be linked, in part, to the type of data one uses (real time vs. historical) and, in part, to the type of empirical analysis one conducts: while narrative and reduced form approaches consistently point to "bad policy" as key to explain the facts, structural VARs favor the "bad luck" conclusion. Given the strong prior of many commentators, some have questioned the ability of structural VARs to detect true sources of variations in the data (see Benati and Surico (2006)).

The most convincing formalization of the " bad policy" hypothesis appears in Lubik and Schorfheide (LS) (2004) who, building on the work of Clarida, et. al. (2000), estimate a three equations New-Keynesian model with Bayesian methods over subsamples and find an indeterminate equilibrium in the first subsample (up to the end of the 1970s) but not in the second one (from the beginning of 1980s up today). Boivin and Giannoni (2006) confirm this conclusion with an alternative estimation technique. One important consequence of this finding is that expectations were driven by non-fundamental forces in the 1970s, and became function of fundamental factors when the Fed strengthened the reaction of the nominal rate to inflation. Despite the fact that the dynamics of expectations are crucial to understand the facts and to assess the credibility of the explanation, no one has formally examined whether expectations fit the role that the indeterminacy-determinacy story of the Great Moderation has given to them. Leduc et. al (2007) studied how much the nominal rate moves in response to expected inflation shocks and whether there has been a change in the magnitude and the persistence of expected inflation shocks, but they do not directly 
examine the importance of inflation expectations in the two regimes.

In this paper we study the role of expectations in the Great Moderation episode. To start with we take a simple New-Keynesian model, parameterized so as to replicate the most salient aspects of LS estimates, and show that there is a state variable entering the solution in the indeterminate regime which fails to appear when the equilibrium is determinate. If expectations play the role of this additional state variable, they should help to predict other endogenous variables in the indeterminate sample and there should be a break in the significance of predictive tests, as we move from the indeterminate to the determinate regime. Moreover, omitting expectations would cause the variance of the shocks to be overestimated in the indeterminate regime but not in the determinate one.

We demonstrate that these two implications are the only testable ones the theory imposes and that existing approaches are unable to detect regime switches. For example, the standard counterfactuals conducted in the literature are uninformative about regime changes because variations in the policy rule imply changes in both the impact coefficients and the lagged responses to shocks, regardless of whether policy changes occur within or across regimes. Moreover, we show that structural methods are unlikely to be more informative than reduced form ones about the type of regime in place because regimes may be "local" to each other. This implies, for example, that the conditional dynamic responses under indeterminacy can be closely approximated under determinacy, as long as the structural parameters are appropriately adjusted.

In our analysis we therefore proceed as follows. We collect alternative measures of one year ahead expectations using survey data (Michigan, Professional, Livingstone), the Greenbook, and the term structure of nominal interest rates. We, then, run several VARs which include output growth, inflation, the nominal interest rate, and a proxy measure of expectations and examine whether (i) the coefficients on lagged expectations are significant and whether their significance changes over time and (ii) whether omitting expectations from the estimated system causes time varying biases in the variance of reduced form shocks. We complement this statistical evidence analyzing whether absence of expectations from the estimated system alters the interpretation of the Great Moderation. Since expectations have been systematically excluded from empirical models, we want to know whether such an omission matters and in what way. Finally, we measure the importance of sunspot shocks and examine whether their elimination could be responsible for the Great Moderation.

Our results suggest that the role of expectations differs from the one postulated by the indeterminacy-determinacy story. In particular, regardless of the specification of the empirical model and the statistics used, we find that (i) lags of expectations are either always 
significant or always insignificant and there is no clear switch over time in their importance in any equation of the system; (ii) reduced form variances estimated in systems with and without expectations display similar features and little evidence of time varying biases; (iii) the economic interpretation of the Great Moderation is largely independent of the exclusion of expectations from the empirical system; (iv) sunspot shocks have little effects on output growth and inflation volatility and persistence and changes in their contribution over time do not line up well with the time variations in these statistics.

The rest of the paper is organized as follows. The next section examines the implications of a simple theoretical model. Section 3 describes our expectation measures. Section 4 presents the empirical evidence. Section 5 discusses the causes of the Great Moderation. Section 6 measures the importance of sunspot shocks. Section 7 concludes.

\section{$2 \quad$ What does theory tells us ?}

To set up ideas it is useful to consider a simple univariate example. Let $y_{t}=\frac{1}{\theta} E_{t} y_{t+1}+e_{t}$, where $e_{t}$ is iid $\left(0, \sigma^{2}\right)$. When $\theta>1, y_{t}=\sum_{j}\left(\frac{1}{\theta}\right)^{j} E_{t} e_{t+j}=e_{t}$; when instead $\theta<1$, $y_{t+1}=\theta y_{t}-\theta e_{t}+v_{t+1} \equiv \theta y_{t}+u_{t+1}$, where $v_{t+1}=y_{t+1}-E_{t} y_{t+1}$. Clearly, if $v_{t+1}=e_{t+1}$, $y_{t}=e_{t}$ also when $\theta<1$. In general, the two solutions will be different and a switch in regime can be equivalently represented with a change in the value of $\theta$ or with the elimination of the expectation shock $v_{t+1}$ from the solution.

Suppose $v_{t+1}$ is a pure sunspot shock. In the indeterminate regime, since $E_{t} y_{t+1}=\theta y_{t}-$ $\theta e_{t}$ and since $y_{t}$ is independent of $e_{t}, E_{t} y_{t+1}$ helps to forecast $y_{t+1}$, even when $y_{t}$ is available. Since this is not true in a determinate regime, two basic conclusions emerge: expectations should help to predict $y_{t+1}$ in the indeterminate regime but not in the determinate one; excluding expectations should make forecast errors larger in the indeterminate regime.

To show that these two basic conclusions carry over to more interesting setups, consider a standard three-equation New-Keynesian model, which includes a log-linearized Euler condition, a log-linearized Phillips curve, and a log-linearized policy rule. While this structure is basic, the implications it delivers about regime switches are the same as those obtained in more complex models with additional shocks. In deviation from a non-stochastic steady state, the equations are:

$$
\begin{aligned}
R_{t} & =\phi_{r} R_{t-1}+\left(1-\phi_{r}\right)\left(\phi_{\pi} \pi_{t}+\phi_{x}\left(x_{t}-z_{t}\right)\right)+e_{R, t} \\
\pi_{t} & =\beta \pi_{t+1 \mid t}+\kappa\left(x_{t}-z_{t}\right) \\
x_{t} & =x_{t+1 \mid t}-\tau\left(R_{t}-\pi_{t+1 \mid t}\right)+g_{t}
\end{aligned}
$$


where $g_{t}=\rho_{g} g_{t-1}+e_{g, t}, z_{t}=\rho_{z} z_{t-1}+e_{z, t}, x_{t}$ is the output gap, $\pi_{t}$ the inflation rate, $R_{t}$ the nominal rate, and the notation $t+1 \mid t$ denotes conditional expectations. Here, $g_{t}$ is a demand shifter, $z_{t}$ exogenously shifts the marginal cost of production while $\beta, \kappa, \tau, \phi_{r}, \phi_{\pi}, \phi_{x}, \rho_{g}, \rho_{x}, \sigma_{e R}$, $\sigma_{g}, \sigma_{z}$ and $\rho_{g z}$, the contemporaneous correlation between $g_{t}$ and $z_{t}$, are parameters.

Table 1: Model Parameterization

\begin{tabular}{|c|cc|c|c|}
\hline \hline Parameter & $\begin{array}{c}\text { Regime 1 } \\
\text { Indeterminate }\end{array}$ & $\begin{array}{c}\text { Regime 2 } \\
\text { Determinate }\end{array}$ & $\begin{array}{c}\text { Regime 1 } \\
\text { Determinate 1 }\end{array}$ & $\begin{array}{c}\text { Regime 1 } \\
\text { Determinate 2 }\end{array}$ \\
\hline$\beta$ & 0.99 & 0.99 & 0.99 & 0.99 \\
$\tau$ & $1.45^{-1}$ & $1.45^{-1}$ & $1.75^{-1}$ & $1.45^{-1}$ \\
$\kappa$ & 0.77 & 0.77 & 0.58 & 0.77 \\
$\rho_{g}$ & 0.68 & 0.68 & 0.74 & 0.74 \\
$\rho_{z}$ & 0.82 & 0.82 & 0.74 & 0.77 \\
$\sigma_{g}$ & 0.27 & 0.27 & 0.29 & 0.33 \\
$\sigma_{z}$ & 1.13 & 1.13 & 1.05 & 1.31 \\
$\sigma_{e R}$ & 0.23 & 0.23 & 0.15 & 0.15 \\
$\phi_{\pi}$ & 0.77 & 2.19 & 1.75 & 1.51 \\
$\phi_{x}$ & 0.17 & 0.30 & 0.82 & 0.87 \\
$\phi_{R}$ & 0.60 & 0.84 & 0.81 & 0.86 \\
$\rho_{g z}$ & 0.14 & 0.14 & 0.14 & 0.14 \\
\hline \hline
\end{tabular}

To describe the population features of this model in different regimes we use a parameterization similar in spirit to the estimates of Lubik and Schorfheide (2004) (see table 1, columns 1 and 2), which were obtained with US data and Bayesian methods over the subsamples (1960:1-1979:2, 1982:4-1997:4), although none of the points we make depends on the exact parameter selection. Note that the only change in the first two columns of table 1 is in the coefficients of the policy rule. As in the univariate example, when the reaction of the nominal rate to inflation is weak $\left(\phi_{\pi}<1\right)$ an indeterminate equilibrium obtains; when the reaction is strong $\left(\phi_{\pi}>1\right)$, a determinate equilibrium emerge.

The log-linearized decision rules for the nominal rate, the inflation rate and the output gap are as follows. For the indeterminate regime, the continuity solution (see Lubik and Schorfheide (2003)) produces:

$$
\left[\begin{array}{c}
\widehat{R}_{t} \\
\widehat{\pi}_{t} \\
\widehat{x}_{t}
\end{array}\right]=\left[\begin{array}{cccc}
-0.24 & -0.41 & -0.33 & -0.28 \\
0.23 & -0.19 & -0.59 & -0.15 \\
0.19 & -0.45 & 0.07 & 0.19
\end{array}\right]\left[\begin{array}{c}
\widehat{R}_{t-1} \\
\widehat{\pi}_{t-1} \\
\widehat{x}_{t-1} \\
\widehat{z}_{t-1}
\end{array}\right]+\left[\begin{array}{c}
\widehat{u}_{1 t} \\
\widehat{u}_{2 t} \\
\widehat{u}_{3 t}
\end{array}\right], \Sigma_{u}=\left[\begin{array}{ccc}
0.31 & & \\
0.96 & 3.39 & \\
-0.15 & -0.42 & 0.40
\end{array}\right]
$$

where $\hat{z}_{t}$ could be either expected inflation, expected output or a combination of the two, while the orthogonality solution (see Lubik and Schorfheide (2003)) delivers: 


$$
\left[\begin{array}{c}
\widehat{R}_{t} \\
\widehat{\pi}_{t} \\
\widehat{x}_{t}
\end{array}\right]=\left[\begin{array}{cccc}
0.62 & 0.03 & -0.17 & 0.01 \\
0.27 & -0.18 & -0.58 & -0.14 \\
0.13 & -0.48 & 0.06 & 0.17
\end{array}\right]\left[\begin{array}{c}
\widehat{R}_{t-1} \\
\widehat{\pi}_{t-1} \\
\widehat{x}_{t-1} \\
\widehat{z}_{t-1}
\end{array}\right]+\left[\begin{array}{c}
\widehat{u}_{1 t} \\
\widehat{u}_{2 t} \\
\widehat{u}_{3 t}
\end{array}\right], \Sigma_{u}=\left[\begin{array}{ccc}
0.05 & & \\
0.03 & 0.17 & \\
-0.08 & -0.41 & 0.98
\end{array}\right]
$$

In the determinate regime we have:

$$
\left[\begin{array}{c}
\widehat{R}_{t} \\
\widehat{\pi}_{t} \\
\widehat{x}_{t}
\end{array}\right]=\left[\begin{array}{ccc}
-0.39 & -0.31 & 0.11 \\
-0.15 & 0.30 & -0.12 \\
-0.23 & -0.16 & 0.44
\end{array}\right]\left[\begin{array}{c}
\widehat{R}_{t-1} \\
\widehat{\pi}_{t-1} \\
\widehat{y}_{t-1}
\end{array}\right]+\left[\begin{array}{c}
\widehat{u}_{1 t} \\
\widehat{u}_{2 t} \\
\widehat{u}_{3 t}
\end{array}\right], \Sigma_{u}=\left[\begin{array}{ccc}
0.09 & & \\
0.24 & 0.98 & \\
-0.21 & -0.55 & 0.89
\end{array}\right]
$$

As these expressions show, there is an additional state variable under indeterminacy when sunspots are present - and the choice of solution is unimportant ${ }^{1}$. Hence, $\widehat{z}_{t-1}$ should help predicting $\left(\widehat{R}_{t}, \widehat{\pi}_{t}, \widehat{x}_{t}\right)$, given a lag of these variables, in the indeterminate regime but not in the determinate one. Moreover, omitting $\widehat{z}_{t-1}$ from the estimated equations would cause the variance of the reduced form shocks to be larger than the true one in the indeterminate but not in the determinate regime. Note that this is different from saying that that the importance of $\widehat{z}_{t-1}$ should change unconditionally across regimes, and that the variance of the shocks in the indeterminate regime is larger than in the determinate one. Unconditionally, several authors have documented that variables which could proxy for $\widehat{z}_{t-1}$ loose their predictive ability for e.g. output and inflation after 1984 (see e.g. Campbell (2004)). but these results have little to say about the implications we care about. Furthermore, the magnitude of the variance of the shocks in the two regimes depends on the parameterization and the choice of solution. For example, two of the three the diagonal elements of $\Sigma_{u}$ are larger in the determinate than in the indeterminate regime under orthogonality. Rather than comparing variances across regimes, we emphasize that omission of $\widehat{z}_{t-1}$ induces biases in the variance of the reduced form disturbances in the indeterminate regime.

Interestingly, while the structural model differs across regimes only in the coefficients of the policy equation, the solution is such that lagged dynamics as well as the variance of the reduced form shocks change. Hence, standard counterfactuals exercises, conducted assuming that there are switches only in the variance or in the coefficients across samples, can not be used to assess whether a regime change has occurred. In addition, since changes within a regime imply changes in the lagged coefficients and in the variances of reduced form shocks of roughly the same magnitude as changes across regimes, it is impossible to use the relative magnitude of their variations to determine the nature of the regime and/or whether it has changed.

\footnotetext{
${ }^{1}$ We are not the first ones to point out this fact. Lubik and Schorfheide (2004), for example, indicate that this is the case, but they do use this implication to derive testable restrictions.
} 
Figure 1 presents the dynamics in response to shocks in the two regimes where, in the case of indeterminacy, we plot both the continuity and the orthogonality solutions. While there are quantitative differences, especially in the impact period, the sign and the shape of the responses are similar across regimes. Hence, when faced with an infinite sample of data from this model, methods focussing on the dynamics induced by structural shocks will find it hard to detect regime switches.
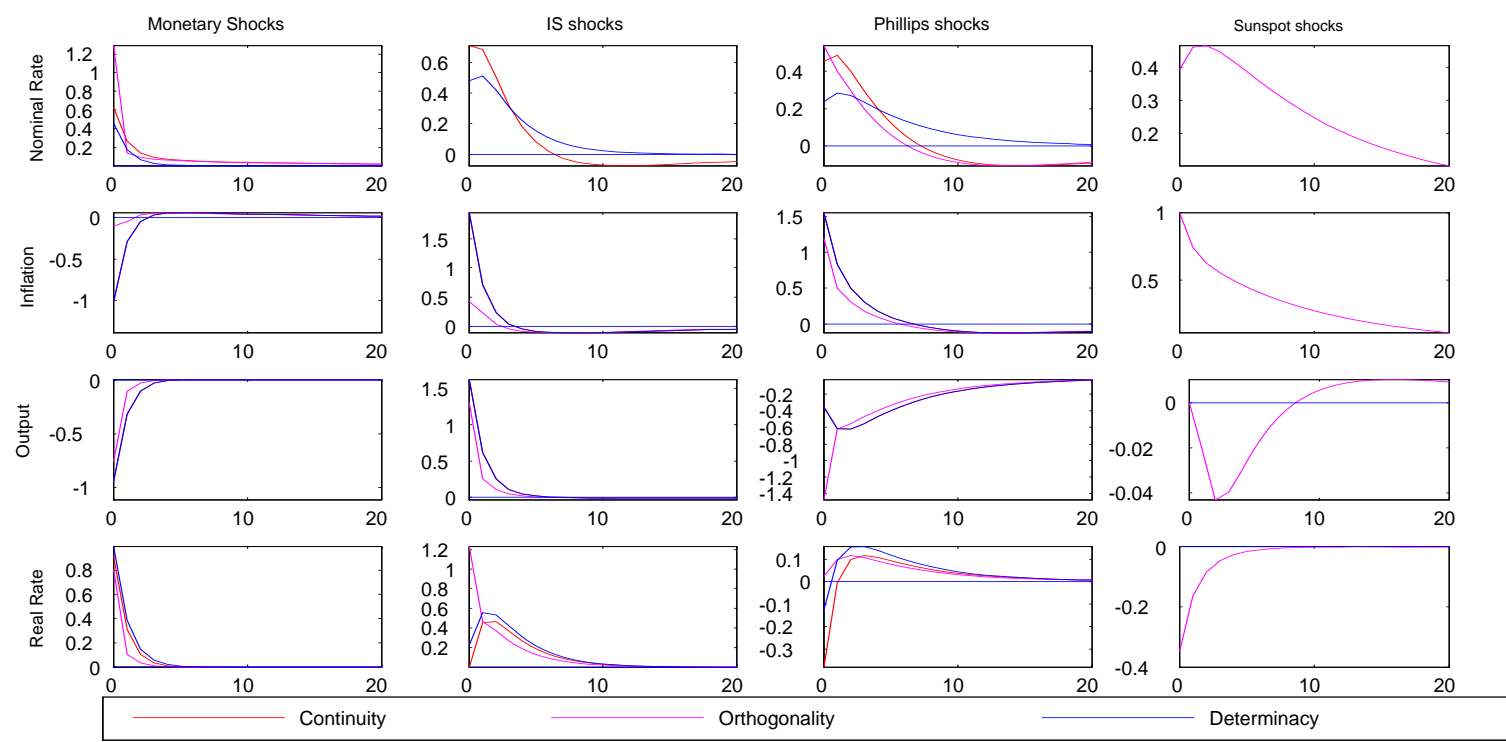

Figure 1: Impulse responses, Determinacy and Indeterminacy

It is often presumed that structural estimation methods have an edge relative to less structural ones in detecting regimes, because they take expectation formation into account. To illustrate the fallacy of such a presumption in our specific case, we take the population dynamics generated by the model under indeterminacy (the continuity solution) as given and ask: are there parameter values which make the dynamics under determinacy "close" to those produced under indeterminacy? Figure 2 shows that this is indeed possible. If rather than taking one parameterization, we take estimated uncertainty seriously and construct response bands for the indeterminate regime using Monte Carlo simulations, these bands would always include the point estimate of the responses under determinacy.

The parameters obtained in the determinate equilibrium are in the third column of table 1. Note that, it is impossible to simply change the variance of the shocks to match the dynamics of the indeterminate solution; that is, the "bad luck" hypothesis is not local to the indeterminacy/determinacy story. However, alternative explanations in which the private sector parameters change together with the structural variances or in which the parameters of the policy rule change together with the structural variance (keeping private sector parameters fixed, see last column of table 1) have this feature. 

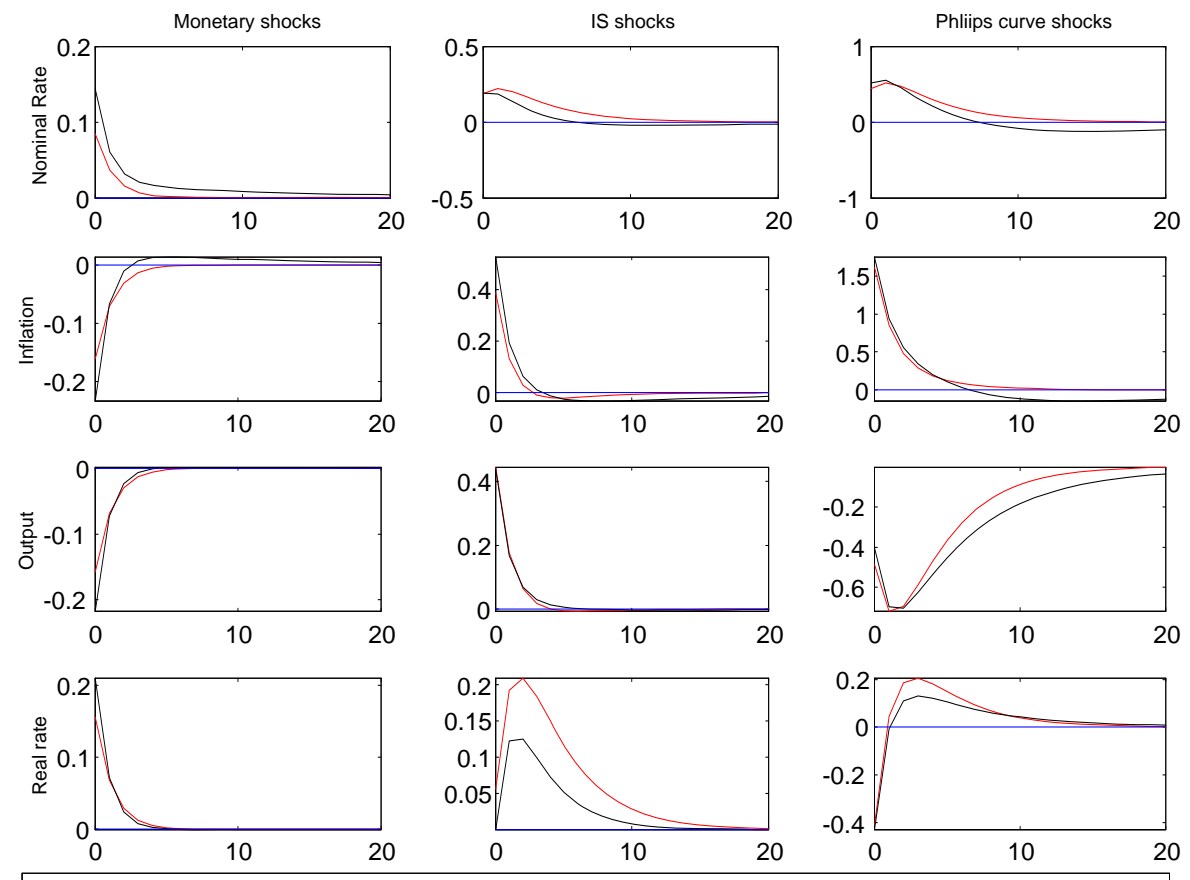

determinacy

indeterminacy

Figure 2: Alternative dynamics for regime 1

In sum, regime changes are hard to detect with standard methods. However, if the indeterminacy/determinacy story is correct expected inflation, expected output, or a combination of the two must be a state variable up to the end of the 1970s but not afterwards, that is, lags of these variables must help in predicting output, inflation, and interest rates, given their lags, up to the end of the 1970s but not afterwards and the change should be a permanent one. Furthermore, omitting expectations from the system should change the variance of reduced form shocks only for samples up to the end of the 1970s. Clearly, if the story is correct and expectations are excluded from the empirical system, one should also expect the interpretation of the Great Moderation to be significantly affected.

In the next section, we focus attentions on the role of inflation expectations as a state variable. Later, we examine how our conclusions change if a measure of output expectations is used in place or in addition to an inflation expectation measure.

\section{Measures of expectations}

Expectations are not observable but there are a number of proxies one could use. Since they differ in the time coverage and in their reliability as predictor of future variables, we dedicate this section to describe their properties and motivate our selection of proxy measures. 
The Michigan survey reports average expected changes in consumer prices for the incoming year and is available quarterly since 1960:1. This survey has 100 respondents each period, covers primarily households, and is conducted before the inflation figure of the middle month of the quarter are available. We assign the forecast to the end of the quarter, giving the survey a bit more information than it actually has. We use the mean forecast as our measure, since median estimates are available only since 1978, despite the fact that Kilian and Inoue (2005) have raised doubts about its reliability.

The Survey of Professional Forecasters, constructed by the Federal Reserve Bank of Philadelphia, has data on the implicit price deflator and real GDP expected yearly changes since 1970:1 (1968:1 for real GDP growth) while CPI forecasts are available only since 1981. The number of respondents changes somewhat with the quarter and the year in which the survey is run, and respondents are primarily members of the business community. As the Michigan survey, it is conducted in the middle of each quarter, but we assign the reported value to the end of the quarter. In this case, we use median forecast as our measure.

The Livingstone survey is biannual - it is conducted in April and October since 1955:1 - and reports eight months ahead level of the non-seasonally adjusted CPI. The number of respondents is smaller than the other two surveys (it covers about 50 economists from industry, government and academia per time period) and this may produce larger or more persistent biases. To make it comparable to the other survey measures, the 8 months expected rate of change is annualized. The median value is used as our estimate.

The Greenbook contains projections of inflation and real GDP growth produced by the staff at the Federal Reserve Board for FOMC meetings. The projections measure the annualized quarter-on-quarter changes of the implicit price deflation and real GDP up to 1996 and of the chain-weighted indices after that date. One year ahead forecasts are available only since 1975:1. Irregularly sparsed annualized two and three quarters ahead forecasts are available since 1968:1 and annualized one quarter ahead forecasts since 1965:4. We fill in missing data using regression methods and use annualized three quarters ahead projections as our basic measure. Also since FOMC meetings are irregularly spaced, quarterly data are constructed using the projections produced by the report which is closest to the middle of each quarter. As with survey measures, we assign this value to the end of the quarter.

The term structure of nominal interest rates also provides an implicit measure of inflation. To construct it, let $f_{t, 4, k-4} \equiv \frac{R_{t, 4}}{R_{t, k}}$ be the forward rate quoted at $\mathrm{t}$ for one year maturity on a bond with settlement period $k$. This rate, which can be computed using the 
returns on one year and any $k$ years nominal bonds, can be decomposed as:

$\left.f_{t, 4, k-4}=r_{t, 4, k-4}^{e}+\pi_{t, 4, k-4}^{e}+\left[f_{t, 4, k-4}-E_{t} \ln R_{4, t+k-4}\right]+\left[E_{t} \ln R_{4, t+k-4}\right]-r_{t, 4, k-4}^{e}-\pi_{t, 4, k-4}^{e}\right]$

where the first term represents the expected one year real rate, the second the one year expected inflation, the third the nominal term premium (the difference between the forward rate and the expected future nominal rate) and the last the real excess return of the expected nominal rate over the expected real rate. While it is typical to assume that the first, the third and the fourth terms of the expression are time invariant - this would allow us to identify the dynamics of expected inflation with those of the forward rate - such an assumption is too heroic for the sample we consider to be credible. As an alternative, we use the rational expectation assumption, regress realized inflation on a constant and the forward rate and take the predicted value as a measure of inflation expectations. This procedure is relatively common in the literature (see e.g. Svensson (1994), or Soderlin (1995)) and make the resulting expectations close to actual inflation. To take into account potential breaks in the path of inflation the regression is actually run on two separate subsamples (up to 1980:2, after 1980:2). An alternative signal extraction approach, where expected inflation is treated as unobservable random walk while the other components in (4) have stationary AR(1) dynamics, produces similar results.

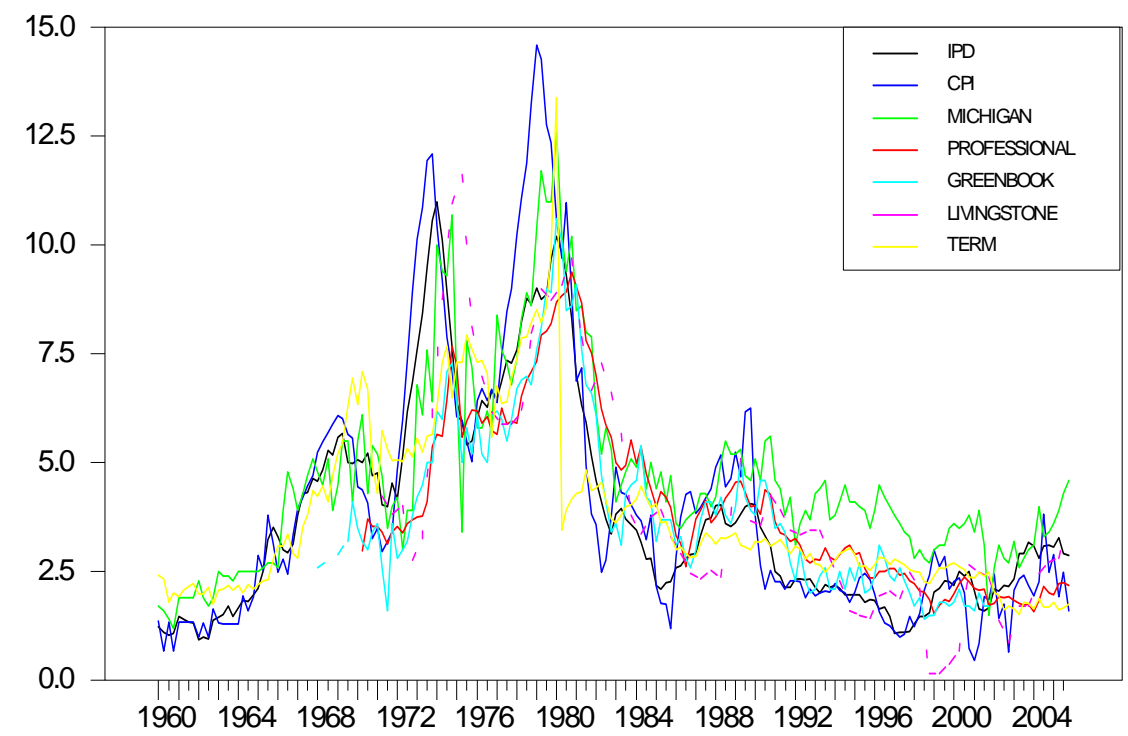

Figure 3: Actual and expected inflation.

Data on the term structure of the nominal interest rates is available at the FRED databank of the Fed of Saint Louis. However, the data reports rates for non-zero coupon bonds. We have managed to recover a comparable data set for zero coupon bonds but only 
for the period 1974:1-2001:4, which makes it too short for our purposes. It turns out that the forward rates implied by the two term structures are very similar in the overlapping sample (contemporaneous correlation 0.98) and the measures of expectations we obtain from the two different series are practically indistinguishable. To maximize the length of the sample, we work with inflation expectations obtained from non-zero coupon bonds, even though the above decomposition is only approximately valid.

While inflation expectations backed out from financial market data are probably more reliable, survey data are publicly available and do not require any statistical model or possibly controversial assumption to back them out. To compare their properties, we plot in figure 3 the time path of the five expected inflation series together with actual inflation computed using the implicit price deflator (IPD) and the CPI (measured here by the seasonally adjusted CPI for all items). Confirming Merha (2002), Michigan expectations are a good predictor of actual inflation up to 1980. The tracking performance deteriorates somewhat over the 1980s, and over the 1990s the reported mean systematically overestimates actual inflation. Professional expectations are better over the whole sample, but in particular episodes (for example, the beginning of the 1980s), they are less reliable than Michigan expectations. Livingstone expectations appear to be free of large or persistent biases, except perhaps in the latest part of the sample. Greenbook projections closely track IPD dynamics, are highly correlated with Professional and term structure expectations, and replicate actual inflation well, except for the early 1980s.

Table 2: Statistics and contemporaneous correlations

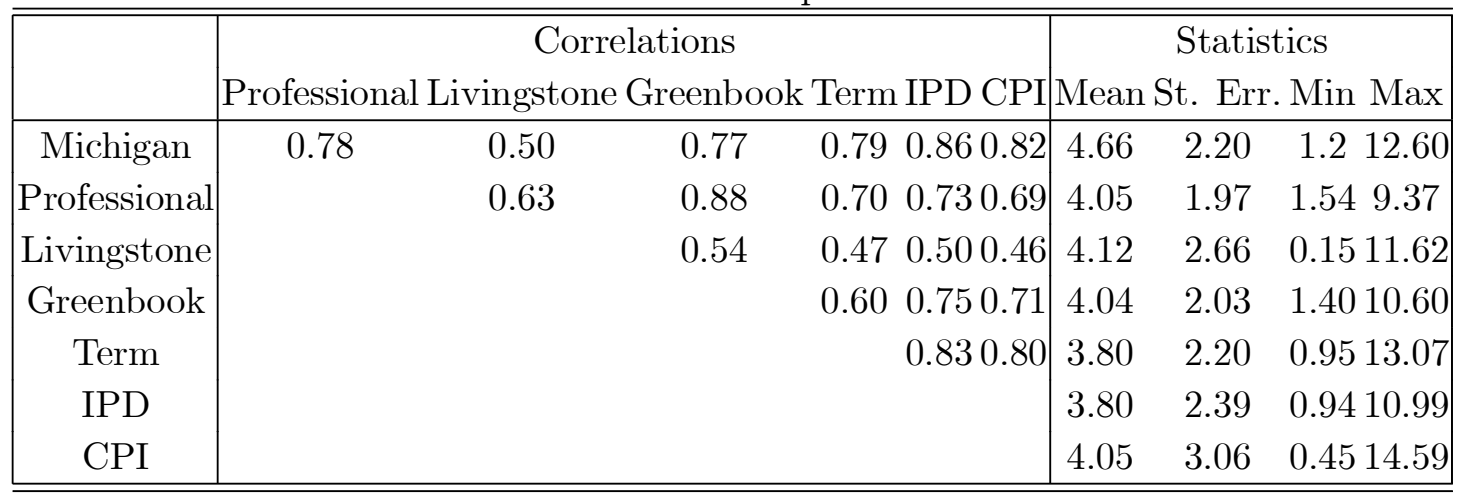

Table 2 shows that Michigan and Term structure expectations are those most highly correlated with actual inflation (regardless of whether it is measured by IPD or CPI) and with each other. In terms of moments of the empirical distribution, Term structure expectations closely replicate those of actual inflation. Hence, we initially focus on Michigan and Term structure expectations and use other measures for robustness checks ${ }^{2}$.

\footnotetext{
${ }^{2}$ When comparing survey measures to actual inflation data one should be aware that they are not mea-
} 


\section{The evidence}

We estimate reduced form VAR models and examine whether lags of inflation expectations matter in a system including real output growth $(\Delta \mathrm{GDP})$, the inflation rate $(\pi)$, a short term nominal rate $(\mathrm{R})$. Data is from the FRED data bank. Output growth is measured by the year-to-year change in GDP, inflation by the year to year change in CPI, all items and the interest rate by the Federal funds rate. While the implications we have derived in section 2 hold for a system where real activity is proxied by the output gap, it can be easily shown that they also hold when output growth is used.

To start with, we use the traditional device of breaking the sample in two even if such approach is problematic for two reasons: since inflation and the nominal interest rate display an inverted U-shaped pattern, it is not clear which break date should be used and whether a subset of the data (the 1979-1982 period) should be omitted or not; using subsamples forces a simultaneous break in all the relationships while the moments of these variables display breaks at different dates.

Table 3: F-tests, p-values

\begin{tabular}{|l|l|l|l|l|l|l|l|l|l|}
\hline \hline & \multicolumn{7}{|c|}{ With Michigan expectations } \\
sample & $60: 1-79: 2$ & $60: 1-80: 2$ & $60: 1-81: 2$ & $60: 1-82: 2$ & $79: 3-05: 4$ & $80: 3-05: 4$ & $81: 3-05: 4$ & $82: 3-05.4$ \\
\hline$\Delta$ GDP & 0.73 & 0.70 & 0.81 & 0.91 & 0.70 & 0.55 & 0.99 & 0.92 \\
$\pi$ & 0.00 & 0.01 & 0.01 & 0.00 & 0.02 & 0.00 & 0.04 & 0.05 \\
$\mathrm{R}$ & 0.07 & 0.00 & 0.11 & 0.24 & 0.00 & 0.01 & 0.10 & 0.05 \\
\hline \hline \multirow{7}{*}{ sample } & $60: 1-79: 2$ & $60: 1-80: 2$ & $60: 1-81: 2$ & $60: 1-82: 2$ & $79: 3-05: 4$ & $80: 3-05: 4$ & $81: 3-05: 4$ & $82: 3-05.4$ \\
\hline$\Delta$ GDP & 0.69 & 0.82 & 0.52 & 0.29 & 0.02 & 0.03 & 0.10 & 0.67 \\
$\pi$ & 0.58 & 0.51 & 0.10 & 0.00 & 0.00 & 0.00 & 0.59 & 0.24 \\
$\mathrm{R}$ & 0.00 & 0.00 & 0.00 & 0.00 & 0.00 & 0.00 & 0.06 & 0.02 \\
\hline \hline
\end{tabular}

Table 3 reports the p-value of an F-test for the exclusion of lags of inflation expectations for a number of subsamples in a VAR with 4 lags. When Michigan expectations are employed, lags of inflation expectations are never important in the output growth equation, always important in the inflation equation and usually important in the nominal rate equation (the exceptions are the samples 1960:1-1981:2 and 1960:1-1982:1). When term

suring the same thing. First, the reported expected rate is an average over quarters rather than an end of the period measure. Second, apart from Professional forecasts, it is not clear if agents forecast CPI levels/changes or headline CPI level/changes. Third, it is not clear if simple or compounded rates are used to construct yearly measures. Fourth, forecasts are typically for non-seasonally adjusted data, while seasonally adjusted data will be used in the exercise. Ang et. al. (2006) have shown that these measurement biases are small and account for none of their forecasting comparison results. 
structure expectations are used, lags of inflation expectations are always significant in the nominal rate equation; significant in the output growth equation in the samples 1979-2005 and 1980-2005, and significant in the inflation equation, if the years 1979-1980-1981 are jointly included.

Table 4: Variances of reduced form shocks

\begin{tabular}{|c|c|c|c|c|c|c|c|c|}
\hline sample & $60: 1-79: 2$ & $60: 1-80: 2$ & $\begin{array}{r}\text { With } \\
60: 1-81: 2\end{array}$ & $\begin{array}{l}\text { h Michigal } \\
60: 1-82: 2\end{array}$ & $\begin{array}{l}n \text { expecta } \\
79: 3-05: 4\end{array}$ & $\begin{array}{l}\text { ations } \\
80: 3-05: 4\end{array}$ & $4|81: 3-05: 4|$ & $82: 3-05.4$ \\
\hline$\Delta \mathrm{GDP}$ & 0.80 & 0.81 & 0.86 & 1.06 & 0.60 & 0.58 & 0.56 & 0.34 \\
\hline$\pi$ & 0.07 & 0.08 & 0.09 & 0.10 & 0.05 & 0.04 & 0.03 & 0.03 \\
\hline $\mathrm{R}$ & 0.50 & 0.75 & 1.47 & 1.96 & 0.93 & 0.92 & 0.46 & 0.15 \\
\hline sample & $60: 1-79: 2$ & $60: 1-80: 2$ & $\begin{array}{r}\text { With te } \\
60: 1-81: 2\end{array}$ & $\begin{array}{l}\text { erm struct } \\
60: 1-82: 2\end{array}$ & $\begin{array}{l}\text { ture expec } \\
79: 3-05: 4\end{array}$ & $\begin{array}{l}\text { ctations } \\
80: 3-05: 4\end{array}$ & $4|81: 3-05: 4|$ & $82: 3-05.4$ \\
\hline$\Delta \mathrm{GDP}$ & 0.80 & 0.81 & 0.83 & 1.00 & 0.55 & 0.53 & 0.51 & 0.34 \\
\hline$\pi$ & 0.10 & 0.10 & 0.10 & 0.10 & 0.04 & 0.04 & 0.04 & 0.03 \\
\hline $\mathrm{R}$ & 0.43 & 0.52 & 1.03 & 1.35 & 0.64 & 0.64 & 0.46 & 0.15 \\
\hline sample & $60: 1-79: 2$ & 60:1-80: & $\begin{array}{r}\text { Witho } \\
60: 1-81: 2 \\
\end{array}$ & $\begin{array}{l}\text { out inflati } \\
60: 1-82: 2\end{array}$ & $\begin{array}{l}\text { Ion expect } \\
79: 3-05: 4\end{array}$ & $\begin{array}{l}\text { tations } \\
80: 3-05: 4\end{array}$ & $4 \mid 81: 3-($ & $82: 3-05.4$ \\
\hline$\Delta$ GDP & 0.83 & 0.83 & 0.88 & 1.07 & 0.62 & 0.60 & 0.56 & 0.35 \\
\hline$\pi$ & 0.10 & 0.10 & 0.11 & 0.13 & 0.06 & 0.05 & 0.04 & 0.04 \\
\hline $\mathrm{R}$ & 0.57 & 0.89 & 1.65 & 2.12 & 1.15 & 1.06 & 0.50 & 0.17 \\
\hline
\end{tabular}

Table 4, which reports the estimated variance of the residuals in a number of subsamples when the two proxies for expectations are used and when inflation expectations are excluded from the system, confirms the outcomes of table 3. For appropriately selected samples, the variances of reduced form shocks in a system where inflation expectations are included decreases over time and a system which excludes inflation expectations has reduced form shocks with marginally higher variability. More importantly, a system where inflation expectations are excluded displays the same qualitative features as systems which include them: for appropriately chosen samples, the variance of all shocks declines.

Hence, tables 3 and 4 do not support the main implications of the theory: the data tells us that if inflation expectations matter, they matter for the whole sample and when they don't, changes are temporary and primarily related to the Volker experiment of the late 1970s.

\section{$5 \quad$ Is the empirical evidence reliable?}

There could many reasons for why the empirical evidence fails to conform with the theory. First, we may be unable to detect a permanent break in the importance of inflation ex- 
pectations because the lag length of the VAR is inappropriately chosen. Note that, given overlapping nature of all expectations measures, a generous lag length is needed to whiten VAR residuals. However, if too many lags are included, lags of other variables could proxy for lags of inflation expectations, making our tests weak. Since the model of section 2 has a $\operatorname{VAR}(2)$ format and since inflation expectation measures induce MA component of order three, a lag length of 4 strikes a balance between the two opposing forces. In tables A.1 and A. 2 we show that changing the lag length from 2 to 8 , has no effect on the conclusions.

Second, our tests may fail because the proxies for expected inflations we employ are plagued by measurement or estimation errors. Since Thomas (1999), Merha (2002), and Ang, et. al. (2006)) have shown that these proxies capture important information about future developments of inflation, it is hard to believe that this is the case. Nevertheless, Faust and Wright (2006) have shown that Greenbook projections are superior to other expectation measures, while Leduc et. al. (2007) claim that Livingstone expectations contain information which is relevant to capture shocks to expectations. We have repeated estimation using Greenbook forecasts - in this case the sample starts in 1968:4 - and Livingstone survey data - in this case data for output growth, inflation and the nominal rate is sampled bi-annually. Tables A.3-A.6 show that the same conclusions obtain. If anything, the evidence for a structural break is even weaker with Livingstone data, while Greenbook projections become more important for output growth and inflation after 1982.

One can also think that our inflation expectation measures are not really forward looking and therefore unsuited for the analysis. To check for this possibility we have constructed an expected inflation measure using the VAR. This measure, which is internally consistent but completely backward looking, is correlated with survey and term structure measures, but not perfectly (roughly 0.6). Therefore, inflation expectations measures do contain an independent forward looking component.

Third, one can easily argue that a four equation VAR is misspecified. If a large scale model were the true data generating process and a four variable system was used, many important variables would be omitted and their presence in VAR residuals could make the detection of regime changes hard. We therefore repeated estimation using a eight variable VAR which includes the previous four variables, consumption growth, investment growth, hours and the growth rate of money. Consumption growth is measured by the year-to-year change in real nondurable private consumption, investment by the year to year change in fixed private investments, hours by total hours in the non-farm business sector and money growth by the year to year change in M2. Two lags are sufficient to whiten the residuals of this system. Tables A.7 and A.8 indicate that in this system inflation expectations have 
an even smaller predictive role in the first part of the sample. Hence, it is harder to find a break in the importance of inflation expectations over time.

Fourth, as argued in section 2, the theory implies that there is an additional state variable under indeterminacy with sunspots. So far we have associated this variable with inflation expectations, but any variable which is correlated with sunspot shocks may do the job. We have repeated estimation using a VAR where output growth expectations are used in place of, or jointly with, inflation expectations - since measures of output growth expectations start only in the mid-late 1960's, the size of the first subsamples is now shorter. Tables A9 and A10 shows that the addition of output growth expectations or the substitution of inflation expectations with output growth expectations leaves the conclusions unchanged.

Campbell (2004) has documented that the predictive power of the expectation measures contained in the Survey for Professional Forecasts (SPF) for output growth has declined since 1984. As mentioned, SPF can not be used for our purposes because the data starts too late to make estimation credible. Nevertheless, it should be pointed out that our conclusions are different because the exercise we conduct is different. First, we are looking for a change in predictive power of output expectations, once a lags of the endogenous variables are used. Second, we looking for changes in the predictive power of lagged rather than current expectations. Tulip (2005) has found that the short term predictability of output growth has increased when Greenbook forecast are used. Our results agree with this evidence.

Fifth, it may be that our tests have low power in small sample. Despite our attempts to maximize the size of the samples, we have only about 80 data points on each side of the potential break date. To check whether small samples may be responsible for our results, we have simulated data from each of the two regimes, using the parameter values reported in table 1, employing either the continuity or the orthogonality solution when generating data from the indeterminate regime. We then constructed two samples of 160 data points (one with 80 data from the continuity regime and 80 from the determinate regime, the other with 80 data from the orthogonality regime and 80 from the determinate regime) and applied our tests to simulated data. Tables A11 and A12 show that, with this DGP, one of the expectational variables would be significant in some equations when up to the first 80 data points are used but not if either more data is included or estimation starts at a later date; and that the variance of the reduced form shocks in a system without inflation expectations is larger than in a system which includes them only if the first 80 data points are used. Benati and Surico (2006) have argued that VARs may be unable to correctly capture regime switches with this DGP. Tables A11 and A12 show that such a claim is generally invalid and full scale Monte Carlo evidence, obtained randomizing all the 
non-policy parameters of the model and available on request, confirm this conclusion.

Sixth, Orphanides (2004) and Orphanides and Williams (2005) have forcefully pointed out that policy decisions are typically taken when preliminary estimates of the relevant quantities are available while empirical analyses trying to understand how policymakers historically behaved, typically employ final estimates. For our exercises, this is a relevant concern since the presence of measurement errors could reduce the ability of our tests to detect breaks. To examine the relevance of this problem we have simulated data from the model of section 2 assuming that private agents take decisions using the correct data while the central bank rule is

$$
R_{t}=\phi_{r} R_{t-1}+\left(1-\phi_{r}\right)\left[\phi_{\pi}\left(\pi_{t}+u_{1 t}\right)+\phi_{x}\left(x_{t}-z_{t}+u_{2 t}\right)\right]+e_{R, t}
$$

where $u_{1 t}$ and $u_{2 t}$ are measurement errors. With the same parameterization we have used in tables A11 and A12, we have simulated two samples with 160 data points (one with 80 data from the continuity regime and 80 from the determinate regime, the other with 80 data from the orthogonality regime and 80 from the determinate regime) and applied our tests to the simulated data. We have considered two situations: classical iid and highly serially correlated measurement errors. Clearly, if measurement error is large anything can happen. Therefore, it is important to appropriately calibrate the variance and the persistence of these errors to make the simulations realistic. The size of the revision error between initial and final estimates of output growth and inflation over the last 40 years shows a small declining trend and its standard error around this trend never exceeds 10 percent of the standard error of series. Therefore, it is conservative to assume that an upper bound for the standard deviations of the two measurement errors is 10 percent of the standard errors of the largest structural shocks. Tables A13 and A14 show that measurement error of both types can not cover up structural changes if they were present.

Finally, we have argued that arbitrarily splitting the sample and forcing the break to be common to all equations is less than ideal to examine the role of expectations over time. Time varying coefficient models are particularly suited for our purpose because they avoid strong restrictions on the nature of the breaks and because they can track the evolution of the relationships. A time varying coefficient specification also allows us to examine the weaker hypothesis that the importance of expectations has declined as we move from the 1970s to the later part of the sample. The model we consider is

$$
w_{t}=X_{t}^{\prime} \theta_{t}+\varepsilon_{t}
$$

where $w_{t}$ is a $4 \times 1$ vector, $X_{t}$ is a matrix including lags of $w_{t}$ and a constant, $\theta_{t}$ is a 
$4(4 p+1) \times 1$ vector, $p$ is the number of lags and $\varepsilon_{t} \sim N\left(0, \Sigma_{t}\right)$. We assume that

$$
\theta_{t}=\theta_{t-1}+u_{t}
$$

where $u_{t}$ is a normal $4(4 p+1) \times 1$ white noise with zero mean, covariance $\Omega$, and paths for $\theta_{t}$ which produce non-converging paths for $y_{t}$ are discarded. We assume that $\Sigma_{t}=L \Omega_{t} L^{\prime}$, where $L$ is a lower triangular matrix, that $\Omega=\operatorname{diag}\left\{\omega_{i t}\right\}$ and that

$$
\log \omega_{i t}=\log \omega_{i t-1}+\eta_{i t}, \quad i=1, \ldots, n
$$

where $\eta_{i t} \sim N\left(0, \sigma_{\eta}^{2}\right)$ and $\eta_{i t}, u_{t} \varepsilon_{t}$ are mutually independent.
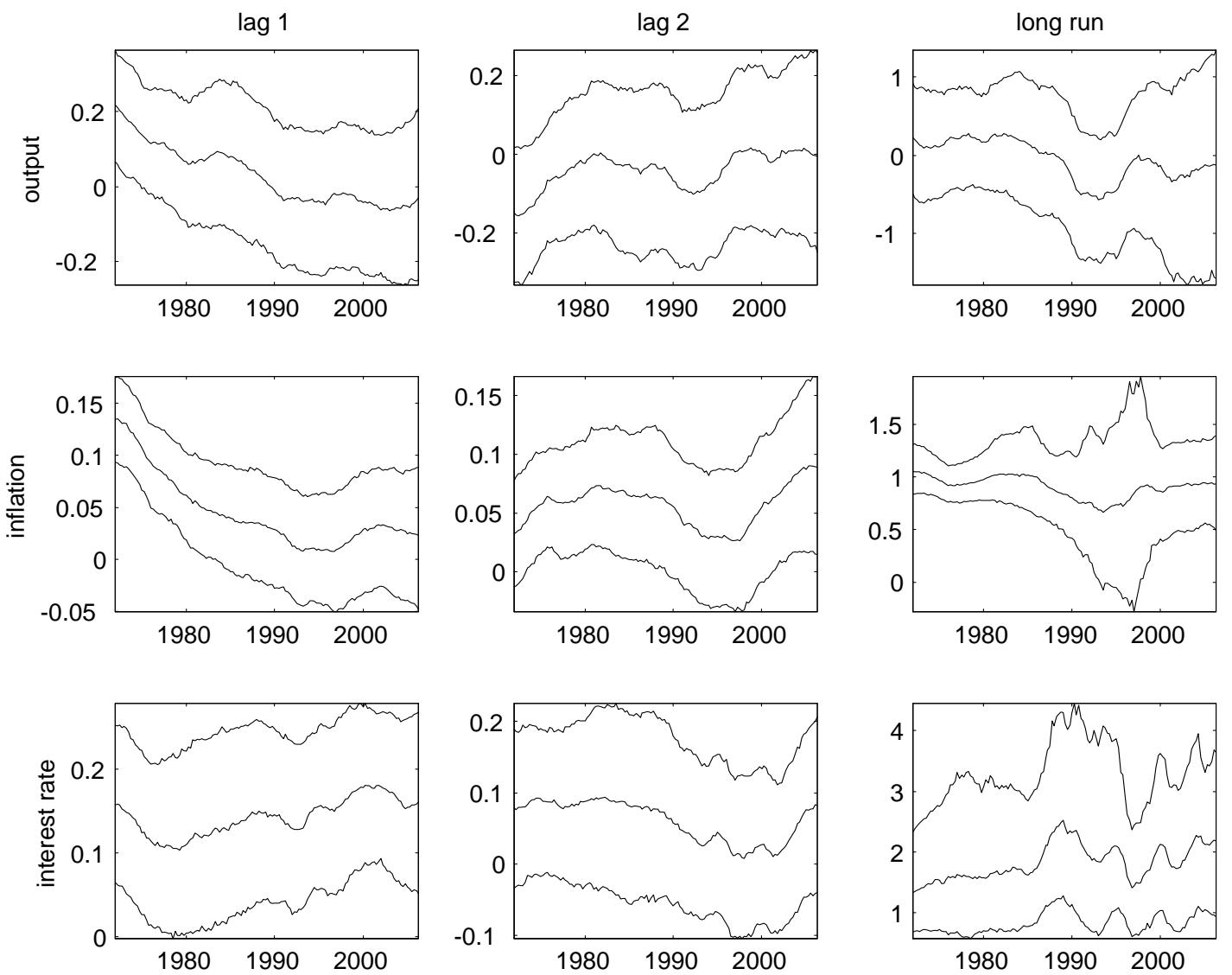

Figure 4: 68 percent posterior intervals for coefficients on lagged inflation (Michigan) expectations. 
We estimate (5)-(7) with Bayesian techniques and non-informative but proper priors setting $p=2$. Since both $\theta_{t}$ and $\Sigma_{t}$ are time varying rather than using classical F-tests for the significance of lags of inflation expectations at each date, we present the evolution of the median and of the $68 \%$ central posterior credible interval for the statistics of interest.

Figures 4 and 5, which plot the evolution of the median and the posterior credible intervals for the lags of inflation expectations and for their long run value in each equation, when Michigan and Term expectations are used, broadly agree with table 3. When Michigan expectations are used, inflation expectations are practically never significant in the output growth equation, and almost always significant in the inflation equation, at least in the long run. The significance of inflation expectations in the interest rate equation depends on the sample, but changes over time in the long run effects are statistically insignificant.

$\operatorname{lag} 1$
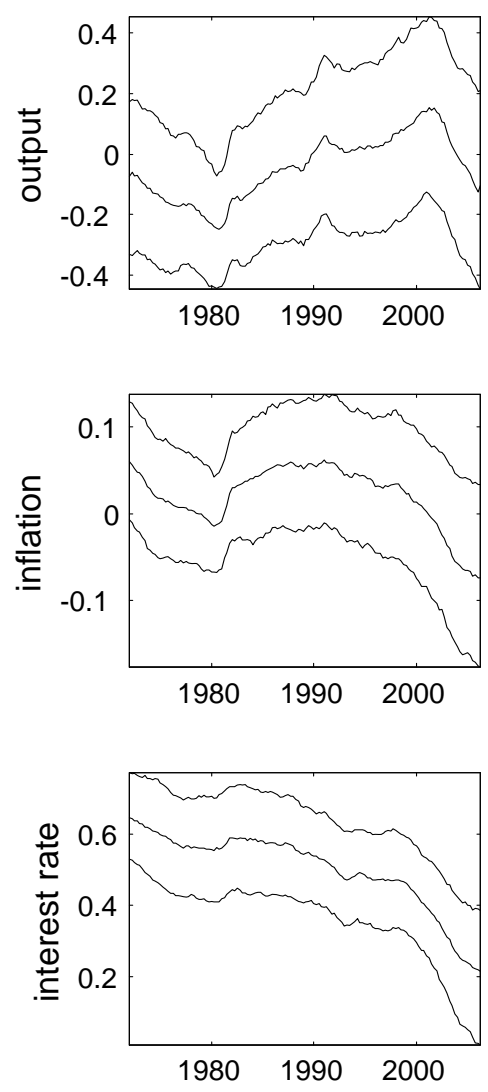

$\operatorname{lag} 2$
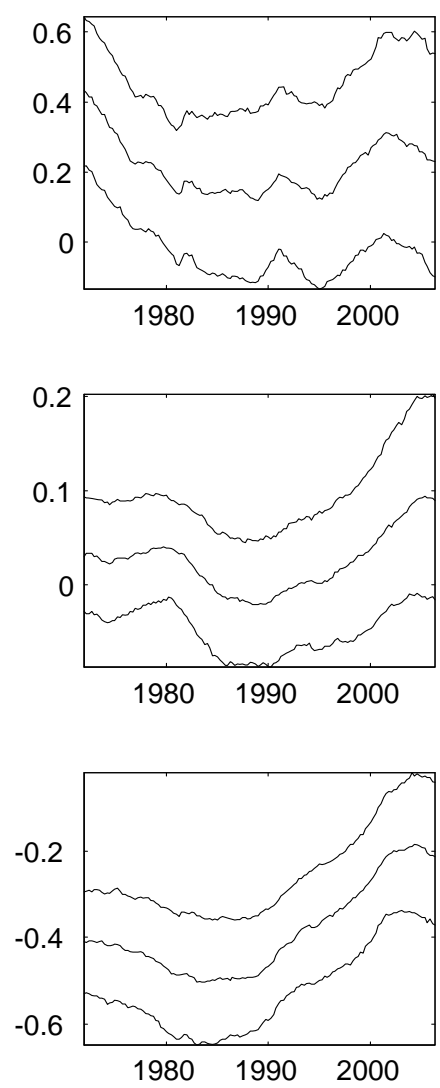

long run
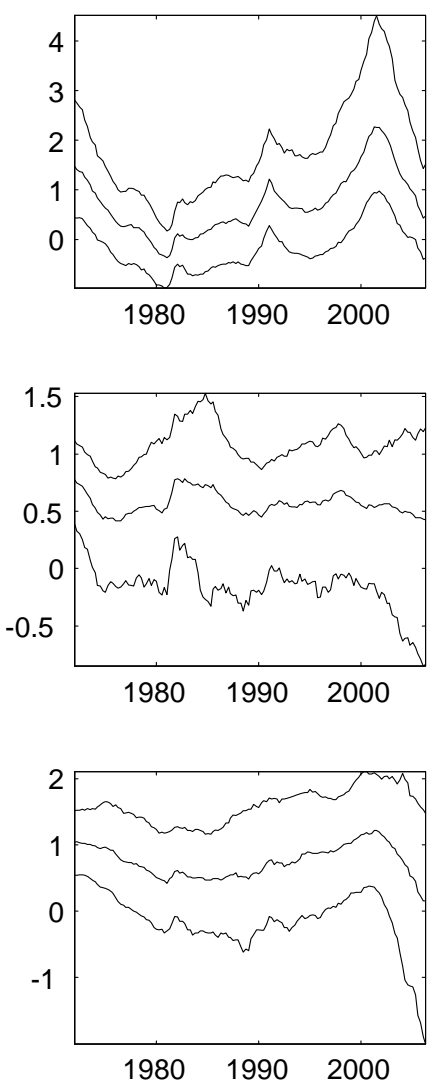

Figure 5: 68 percent posterior intervals for coefficients on lagged inflation (Term) expectations. 
When Term expectations are used the evidence is more mixed. Nevertheless, it is still true that the importance of inflation expectations in the output growth equation is small and somewhat increasing since the early 1980s while for the other two equations the effect is time varying but inconsistent with the hypothesis of interest. For example, decreases in the median value of the coefficient of the first lag in the interest rate equation are compensated by increases in the median value of the coefficient of the second lag. Overall, inflation expectations are more important after 1982.
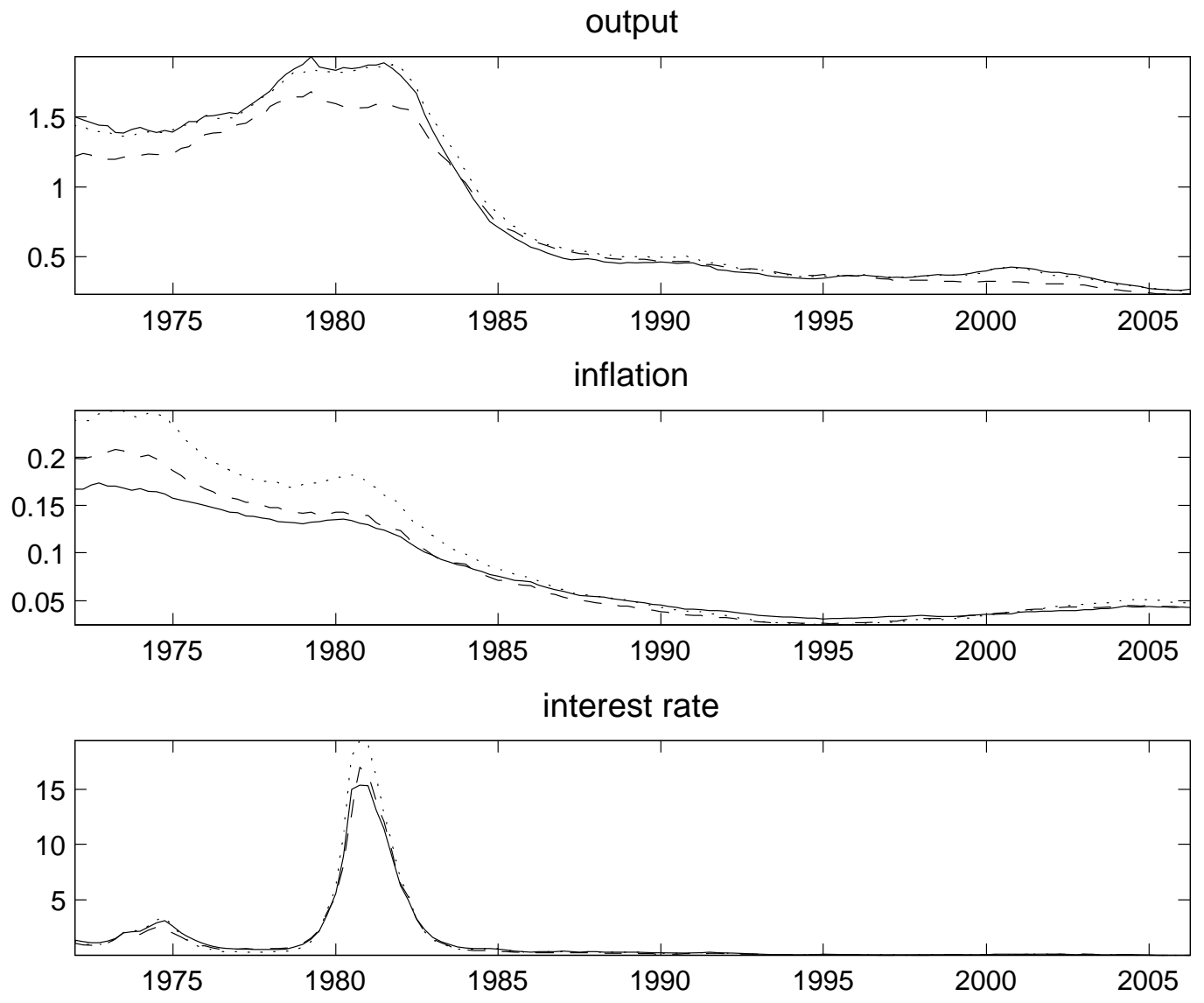

Figure 6: Variances of VAR shocks, solid Michigan, dashed Term, dotted no expectations.

Figure 6, which reports the posterior median of the variance of the reduced form shocks with inflation expectations (Michigan solid line, Term dashed line) and without them (dotted line), also broadly agrees with table 4 . For instance, there is a general decline in the 
variability of the reduced form shocks over time which is similar in magnitude and timing across measures of inflation expectations; including or excluding inflation expectations from the system hardly changes the time path of the reduced form variances. Furthermore, given the considerable uncertainty associated with point estimates, differences in systems with and without inflation expectations are a-posteriori insignificant at any date in the sample.

To conclude, regardless of the measure of employed, of the specification of the VAR and the horizon where we measure the effect, of whether we allow coefficients to be time varying or not, and of other specification choices, the importance of expectations does not decline as we move from the 1970s to the end of the sample, neither in the sense of a structural break nor in the sense of a slow moving but unidirectional change.

\section{Explaining the Great Moderation}

The statistical analysis we have presented is silent as to whether the absence of inflation expectations from an empirical model alters our understanding of the Great Moderation episode. If inflation expectations truly mattered up to a certain date, existing analyses, which systematically exclude them from the empirical system, are likely to be flawed.

To study the sources of the Great Moderation we need to identify structural shocks. The restrictions we use are in table 5. Gambetti et. al. (2005) showed how they can be obtained from a DSGE model featuring monopolistic competitive firms, rational consumers and rules for monetary and fiscal policy, and that they are robust, in the sense that they hold as the structural parameters drift within a reasonable range.

Table 5: Identification restrictions

\begin{tabular}{|l|l|l|l|}
\hline \hline & GDP & $\pi$ & $\mathrm{R}$ \\
\hline Supply/sunspot & $\geq 0$ & $\leq 0$ & $\leq 0$ \\
Real Demand & $\geq 0$ & $\geq 0$ & $\geq 0$ \\
Monetary & $\geq 0$ & $\geq 0$ & $\leq 0$ \\
\hline \hline
\end{tabular}

The restrictions in table 5 are satisfied in the model of section 2 and robust, not only to the parameterization of the model, but also to the horizon at which the analysis is conducted. After some experimentation, we impose restrictions at horizons zero and one.

In the introduction we have characterized the "Great Moderation" phenomena as a considerable fall in the volatility and the persistence of output growth and inflation. We measure persistence as the height of the structural spectrum of output growth and inflation at frequency zero and volatility as the area under the structural spectrum of the two 
variables. These statistics, computed in a four variables TVC-VAR(2) when Michigan expectations are used, are reported as continuous lines in figure 7. They display two sharp peaks, around 1974 and 1981; a considerable decline after the second peak; and since 1985, the persistence and the volatility of both output and inflation have been stable and low relative to the 1970s. Figure 7 also presents the individual contribution of the three identified shocks: starred lines represent the contribution of supply/sunspot shocks, dotted lines the contribution of real demand shocks and dashed lines the contribution of monetary shocks. These lines report the persistence and volatility of output growth and inflation that would emerge if only one type of structural shocks was present at each date.
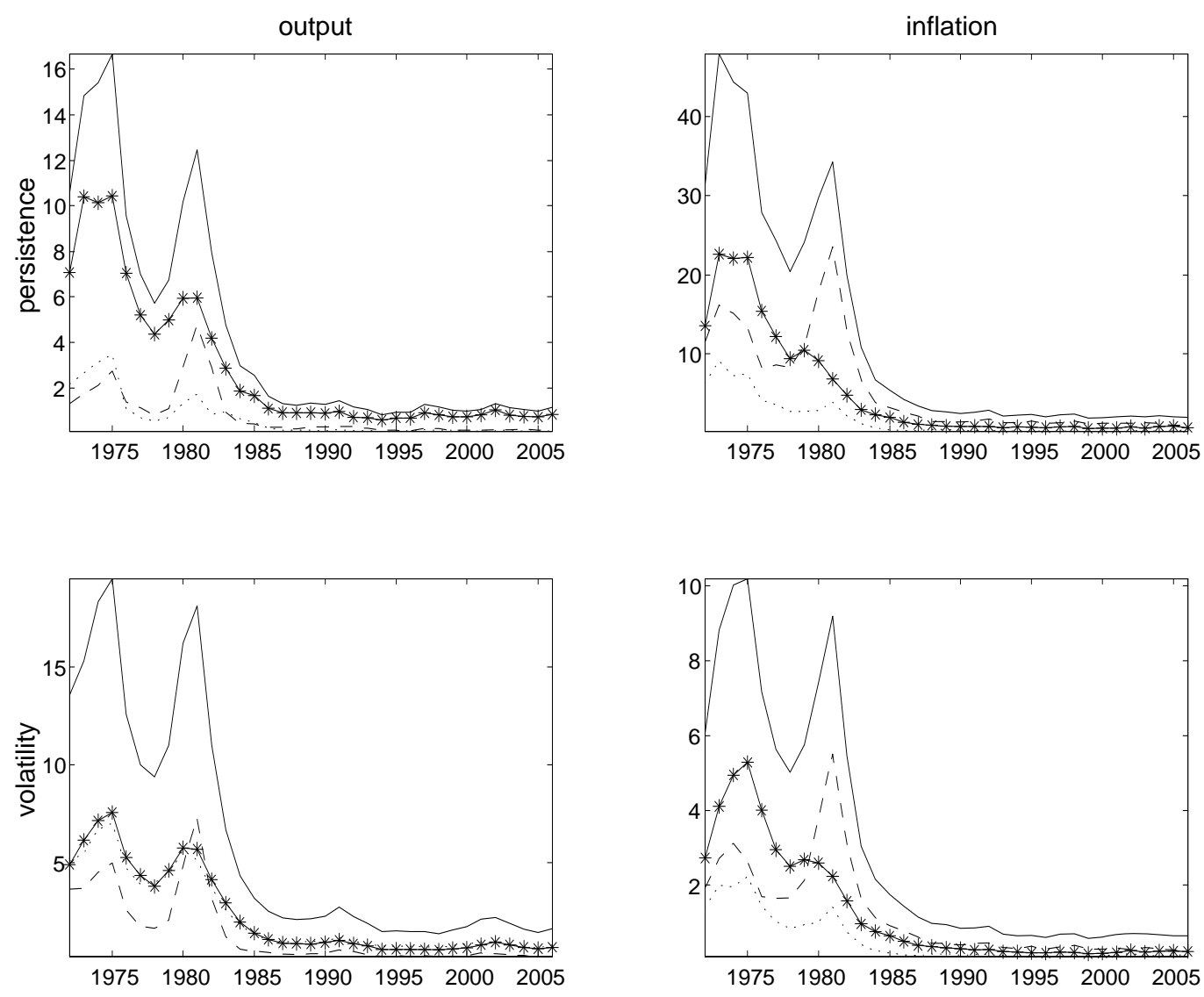

Figure 7: Contribution of supply (stars), real demand (dotted), and monetary (dashed) shocks to inflation and output growth persistence and volatility.

Supply/sunspot shocks are the largest contributors to both the 1974 and 1981 peaks 
in the persistence and volatility in output growth. Monetary shocks contribute little to the 1974 peak, but become more important for the 1981 peak. Supply/sunspot shocks contribute most to the peaks in inflation persistence and volatility in 1974, while monetary shocks are the sole contributor to the 1981 peak - the contributions of supply/sunspot and real demand shocks consistently decline since 1975 for both statistics. Hence, our structural VAR indicates that i) inflation volatility (and persistence) would have been lower since the mid 1970s, hadn't not been for the Volker experiment and ii) the fall in inflation volatility (and persistence) predates the adoption of a more aggressive monetary policy stance.
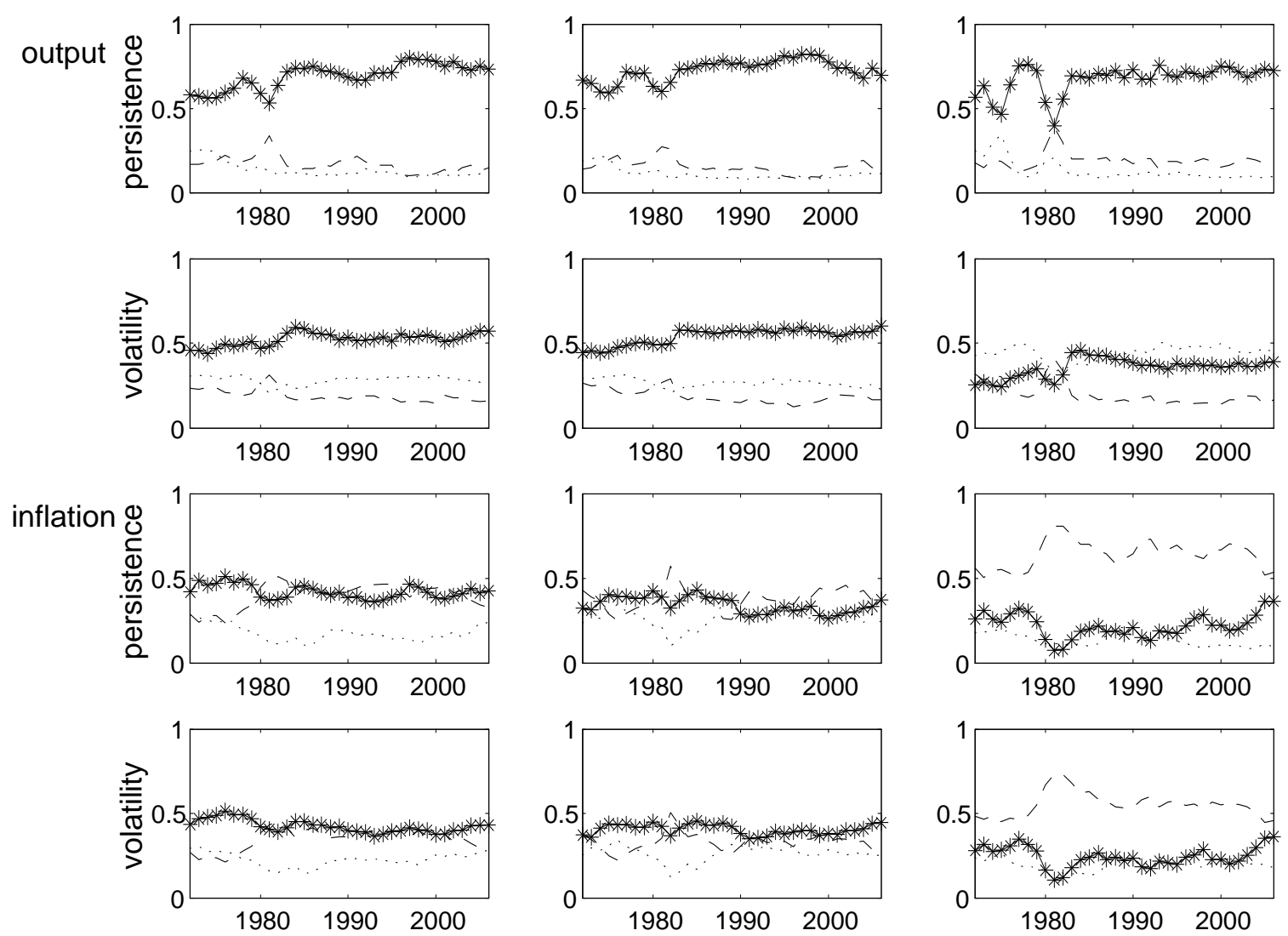

Figure 8: Share contribution of shocks: star supply shocks, dotted real demand shocks, dashed monetary shocks; colomn 1 Michigan, colomn 2 term, colomn 3 no expectations.

Would our conclusions change if we exclude inflation expectations from the VAR? Figure 
8 reports the proportion of inflation and output growth volatility and persistence explained by the three identified shocks at each date in a TVC-VAR with Michigan expectations (first column), Term expectations (second column) and no expectations (third column). Most of our conclusions are unchanged if we inflation expectations are absent from the system. For example, supply and real demand shocks are crucial to characterize the time profile of output growth volatility and persistence while monetary shocks are important to understand only the 1981 peaks. However, when inflation expectations are excluded, monetary shocks become the most important driver of inflation persistence and volatility thought the sample. Notice that the timing of the changes in the three columns is very similar. Hence, even in an economic sense, inflation expectations fail to conform to the role that the indeterminacy/determinacy story has given to themThe results of figures 7 and 8 do not depend on the measure of expectations employed. For example, we have substituted Michigan and Term expectations with a synthetic measure of output and inflation expectations (the principal component obtained from all measures of inflation and output expectations we have available). If anything, differences with the case where expectations are omitted, are less evident with this measure.

\section{Do sunspot shocks matter?}

The analysis of section 6 has not tried to identify the contribution of sunspot shocks to variations in output growth and inflation volatility and persistence. One reason is that, as figure 1 shows, the dynamics of output, inflation and the nominal rate induced by an orthogonal sunspot shock are qualitatively similar to those induced by a Phillips curve shock. However, figure 7 showed that what we called supply/sunspot shock has an important role in explaining the volatility and persistence bursts of 1974 and 1981 and that the time path of the volatility and persistence due to these shocks is declining over time. Could it be that what we call supply shocks are really shocks to expectations? Could it be that even if absence of inflation expectations causes minor changes to the interpretation of the Great Moderation, sunspot shocks matter for output growth and inflation volatility and persistence up to a certain date but not afterwards? Trying to separate the two types of shocks is difficult in a four variable system. In theory, the real rate responds differently to the two shocks - it converges to zero from below in response to sunspot shocks and from above in response to Phillips' curve shocks (see figure 1), but changes in the parameterization and in the model specification change in the dynamics induced by these shocks.

Nevertheless, conditional on the model and its parameterization, we impose the theoret- 
ical shape restrictions on the real rate implies by the VAR and ask: what is the contribution of sunspot shocks to the statistics presented in figure 7 ?
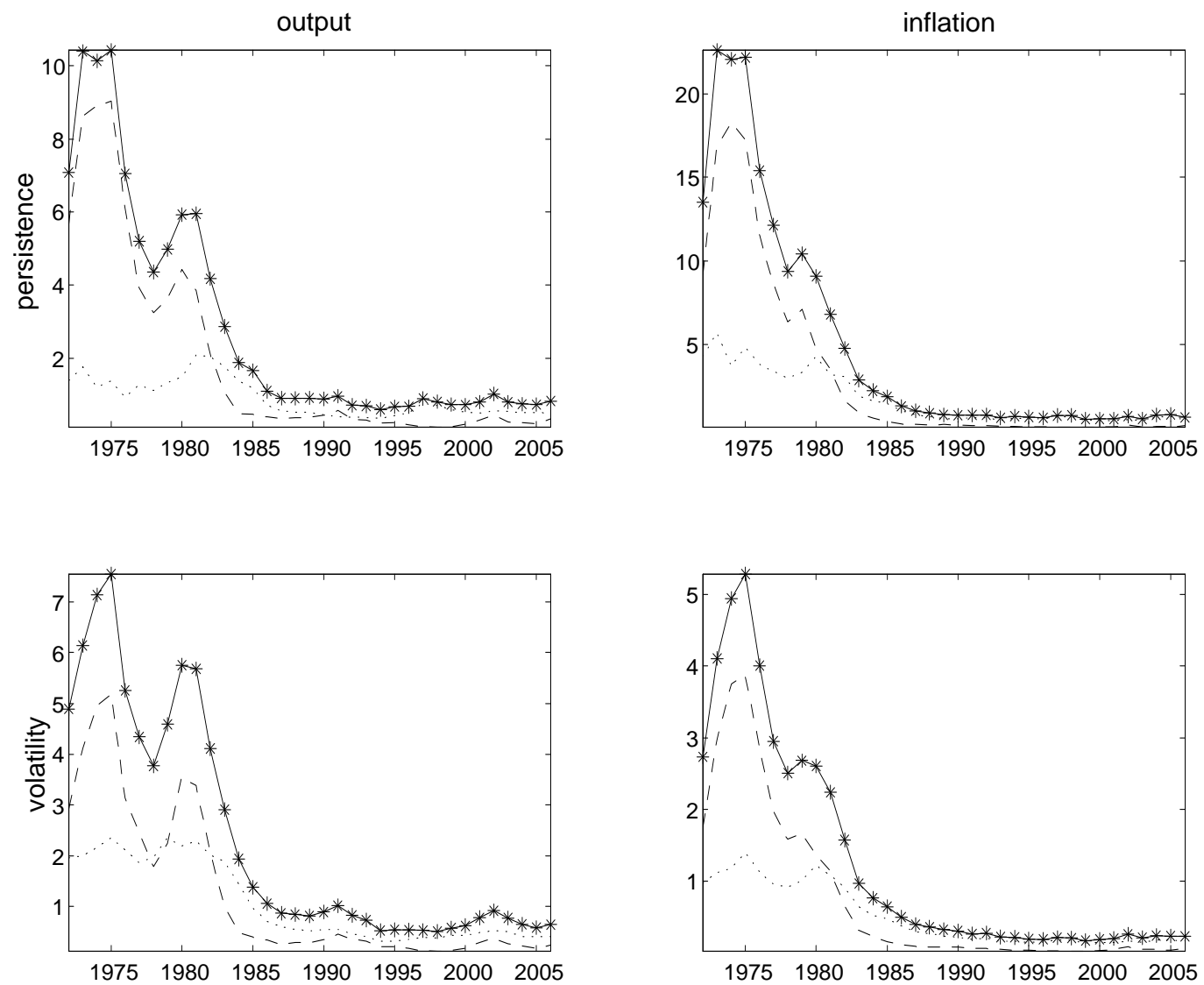

Figure 9: Contribution of sunspot (dotted) and supply (dashed) shocks to output and inflation volatility and persistence.

Figure 9 reproduces the path of the statistics due to the combined effect of supply and sunspot shocks reported in figure 7 (line with stars) and shows the contribution of the two components (sunspot dotted, supply dashed) when orthogonality between structural and sunspot shocks is assumed. Output growth and inflation persistence would have been much lower in the 1970s and the change much more contained if only sunspot shocks where present. Also, the fall in output growth persistence would have occurred only since the mid-1980s. Similarly, output growth and inflation volatility would not display the two peaks in 1974 and 1981 had their been only sunspot shocks and the decline in the 1980s and 1990s would 
have been minor. Hence, while sunspot shocks matter - their contribution is comparable to the one of demand shocks, at least for inflation - the time path they induce fails to line up with the dynamics of persistence and volatility in output growth and inflation produced by the structural VAR.

We want to stress that the evidence in figure 9 is suggestive: in a three equation model it is difficult to find sharp implications to extract sunspot shocks and the restrictions on the real rate we have used are not entirely robust: there are parameter combinations which imply that sunspot shocks look like demand shocks. These parameterizations, however, have the disadvantage that sunspot shocks can not be interpreted as stagflation shocks.

It is worth contrasting our evidence on sunspots with what is available in the literature. Leduc et. al. (2007) identify shocks to expectations using delay restrictions and found that the response of the nominal interest rate is quite different in the 1970 and afterwards. However, the shocks they identify do not induce the same dynamics as the sunspot shocks of figure 1 and this makes the comparison difficult. Lubik and Schorfheide (2004) and Boivin and Giannoni (2006) have estimated the model of section 2 with structural methods, but they do not address the question of how much sunspots matter to explain the Great Moderation episode. Boivin and Giannoni conduct some counterfactuals but, as indicated in section 2, these are not informative about regime switches. Also, the conclusions of all three papers are based on subsample analysis, which, as we have argued, may give a distorted view about the role of sunspots when the data displays U-shaped patterns.

\section{Conclusions}

This paper examines whether the restrictions imposed by a simple indeterminacy-determinacy story of the Great Moderation are satisfied. Using a New-Keynesian model, we show that there is an additional state variable in the indeterminate regime which fail to appear in the determinate one; that standard counterfactuals may have hard time to detect regime changes; and that several explanations are "locally" indistinguishable from the indeterminacy-determinacy story. Using several VAR models we study whether the significance of lagged expectations changes over time; whether omitting expectations from the estimated system causes time varying biases in the variance of reduced form shocks; and whether the absence of expectations alters the interpretation of the Great Moderation.

We find that (i) there is no clear switch over time in importance of lags of expectations in any equation of the system; (ii) reduced form variances estimated in systems with and without expectations display similar paths and little evidence of time varying biases; (iii) 
the economic interpretation of the Great Moderation episode is roughly independent of the inclusion or the exclusion of expectations from the system; (iv) the contribution of sunspot shocks to output growth and inflation volatility and persistence over time do not line up well with the time variations in these statistics.

We show that the empirical results we obtain are robust to a number of potential empirical problems. Therefore, if one insists on taking the bad policy hypothesis as a benchmark, one has to conclude that the model we have used is inappropriate. While the implications we emphasize hold in larger system with additional frictions (such as habit in consumption or wage stickiness), some omitted features which could matter.

First, the model of section 2 assumes that agents are unaware of the possibility that a regime shift may occur and, when it occurs, they never believe there will be a switch back. Davig and Leeper (2007) have recently studied economies where regimes change in a Markov chain fashion and agents are aware of the law of motion of the switches. In this type of economies, the equilibrium is either determinate or indeterminate for the whole sample - this is consistent with the fact that the role of expectations is unchanged over time. Moreover, even if the equilibrium is globally determinate, bad policy can contribute to volatility and persistence bursts. The fact that we detect a fall in the volatility and in the explanatory power of structural shocks over time is therefore in line with an explanation of the Great Moderation where the equilibrium is always determinate but the 1970s were a period of bad policy and the following decades were not.

Empirical evidence suggesting that the case for bad policy in the 1970s is overstated comes from the work of Orphanides and Williams (2005), who find little evidence of violation of the Taylor principle in the 1970s, once real time data are used; and by Duca and Wu (2007), who pointed out that the presence of regulation-Q made the effective real interest rate very different from the ex-post real rate and that, with this rate, the Taylor principle is almost never violated in the 1970s.

Second, the model neglects any form of learning which, e.g., Orphanides and Williams (2004) have found important in the explaining the experience. In learning models expectations become a state variable, regardless of the monetary regime in place. Therefore, our results are not necessarily inconsistent with a indeterminate-determinate story were agents learn over time about changes in the economy (see Schorfheide (2005)). Furthermore, with learning the coefficients of the reduced form representation of the model will be time varying - which is what we find when we allow the coefficients to drift over time.

Third, the model assumes that there is no frictions in the flow of information. In models where information is sticky, like those examined in Mankiw and Reis (2006), the role 
of inflation expectations does not necessarily changes with the regime. This is because expected inflation is generated with information contained in lags of inflation. Sticky information models, however, have one counterfactual implication: inflation expectations should be almost perfectly correlated with lagged inflation. In our data, the correlation is small.

Hence, while the theoretical restrictions implied by the model of section 2 are rejected, it is difficult to draw general conclusions about more sophisticated versions of the bad policy hypothesis which allow for learning, misperception or informational frictions. To examine the role of expectations in these models, one needs to refine our empirical investigation in various ways. First, a small system of equations is not the best vehicle to distinguish alternative hypotheses. A larger scale model, while more difficult to estimate and identify, could help to do this and provide a more convincingly way to separate sunspot from other shocks. Second, to better understand the experience, it is important to measure the effects of inflation expectations shocks on output growth and inflation volatility and persistence in other ways. One could do this with more or less structural methods. The mix of reduced form and semi-parametric analysis we used is robust to model misspecification but, obviously, less informative about these issues. Third, it is also crucial to examine how expectations react to structural shocks and whether there are changes in their responses over time. We leave all these refinements for future research. 


\section{References}

Arias, A., G. Hansen and L. Ohanian (2006), Why have Business Cycle Fluctuations become Less Volatile?, NBER Working Paper No. 12079.

Benati, L. and H. Mumtaz (2005), "The great stability in the UK: Good policy or good luck?", forthcoming, Journal of Money, Banking and Credit.

Benati, L. and P. Surico (2006), VAR analysis and the Great Moderation, manuscript, ECB and the Bank of England.

Blanchard, O.J. and J. Simon (2000), "The Long and Large Decline in U.S. Output Volatility", Brookings Papers on Economic Activity, 1, 135-147.

Boivin, J. and M. Giannoni (2006), "Has Monetary Policy Become More Effective Powerful?", Review of Economics and Statistics 88(3), 445-462.

Campbell, J. and Z. Herkovitz (2006), "The Role of Collateralized Household Debt In Macroeconomic Stabilization", Fed of Chicago, manuscript.

Canova, F. (2005), "Monetary Policy and the Evolution of the US economy: 1948-2002", available at www.econ.upf.edu/crei/people/canova.

Canova, F., Gambetti, L., and E. Pappa (2007), " The Structural Dynamics of Output Growth and Inflation: Some International Evidence", Economic Journal, 117, C167-C191.

Clarida, R., Gali, J. and M. Gertler (2000), "Monetary Policy Rule and Macroeconomic Stability: Evidence and Some Theory", Quarterly Journal of Economics, CXV, 147-180.

Cogley, T. and T.J. Sargent (2001), "Evolving Post-World War II U.S. Inflation Dynamics", NBER Macroeconomic Annual, 16.

Cogley, T. and T.J. Sargent (2005), "Drifts and Volatilities: Monetary Policies and Outcomes in the Post WWII U.S. ", Review of Economic Dynamics, 8, 262-302.

Campbell, S. (2004), "Macroeconomic volatility, predictability and uncertainty in the Great Moderation. Evidence from the Survey of Professional Forecasts", Finance and Economics discussion paper 2004-52, Federal Reserve Board.

Davig, T. and E. Leeper, (2007), "Generalizing the Taylor principle" American Economic Review, 97, 607-635.

Duca, J. and T. Wu, (2007), " Regulation and the Neo Wicksellian Approach to Monetary Policy", Federal Reserve Bank of Dallas, manuscript.

Faust, J. and J. Wright, (2006), "Comparing Greenbook and Reduced form forecasts using a large real-time dataset", John Hopkins University, manuscript.

Gambetti, L., Pappa, E. and F. Canova (2005), "The Structural Dynamics of US Output and Inflation: What Explains the Changes? (with appendix)", CEPR working paper 5879, 
forthcoming, Journal of Money, Banking and Credit.

Gordon, R. (2005), "What caused the decline in US Business cycle volatility?", NBER working paper 11777.

Kilian L. and A. Inoue (2005), "Do actions speak louder than words? Household expectations of inflation based on micro consumption data", University of Michigan, manuscript.

Jerman, U. and V. Quadrini (2006), "Financial Innovation and Macroeconomic Volatility", NBER working paper 12308.

Leduc, S., Sill. K. and T. Stark (2007), "Self-fulfilling Expectations and the Inflation of the 1970s: Evidence from the Livingstone Survey", Journal of Monetary Economics, 54, 433-459.

Lubik, T. and F. Schorfheide (2003), "Computing Sunspot Equilibria in Linear Rational Expectations Models", Journal of Economic Dynamics and Control, 28, 273-285.

Lubik, T. and F. Schorfheide (2004) ,"Testing for Indeterminacy: An application to US monetary Policy", American Economic Review, 94, 190-217

Mankiw, G and R. Reis (2006), "Sticky information in general equilibrium", NBER working paper 12605 .

McConnell, M. and G. Perez Quiroz (2001), "Output fluctuations in the US: what has changed since the early 1980s?", American Economic Review, 90, 1464-1476.

Merha, Y. (2002), "Survey Measures of Expected Inflation: Revisiting the Issue of the Predictive Content and Rationality", Federal Reserve Bank of Richmond, Economic Quarterly, 88, 17-37.

Orphanides, A. (2004), "Monetary Policy Rules, Macroeconomic Stability, and Inflation: A View from the Trenches", Journal of Money, Banking and Credit, 36, 151-176.

Orphanides, A. and J. William (2004), "Imperfect knowledge, Inflation expectations and Monetary policy", in B. Bernanke and M. Woodford (eds.) The inflation targeting debate, Chicago, Il: Chicago University Press.

Orphanides, A. and J. William (2005), "The decline of Activist Stabilization Policy, natural rate misperceptions, learning and expectations", Journal of Economic Dynamics and Control, 29, 1927-1950.

Primiceri, G. (2005), "Time Varying Structural VAR and Monetary Policy, Review of Economic Studies, 72, 453-472.

Schorfheide, F. (2005), "Learning and Monetary Policy Shifts", Review of Economic Dynamics, 8, 392-419.

Sims, C.A. and T. Zha (2006), "Were there Regime Switches in US Monetary Policy", American Economic Review, 96(1), 54-81 
Soderlin, P. (1995), "Forward Interest Rates as Indicators of Inflation Expectations", IIES manuscript.

Svensson, L. (1994), " Monetary Policy with flexible exchange rates and forward interest rates as indicators", Bank of France, Cahier economique and monetaires, 43, 305-322.

Stock, J. and M. Watson (2002), "Has Business Cycle Changed and Why?", NBER Macroeconomic Annual, 17, 159-218.

Stock, J. and M.Watson (2004), "Understanding Changes in International Business Cycle Dynamics", Journal of the European Economic Association, 3, 968-1006.

Thomas, L. (1999), "Survey Measures of Expected Inflation", Journal of Economic Perspective, 13, 125-144.

Tulip, P. (2005), "Has output become more Predictable? Changes in Greenbook forecast accuracy", Finance and Economics discussion paper 2005-31, Federal Reserve Board. 
Appendices 
Table A.1: F-tests, p-values

1 lags

\begin{tabular}{|l|l|l|l|l|l|l|l|l|l|}
\hline \hline & \multicolumn{7}{|c|}{ With Michigan expectations } \\
sample & $60: 1-79: 2$ & $60: 1-80: 2$ & $60: 1-81: 2$ & $60: 1-82: 2$ & $79: 3-05: 4$ & $80: 3-05: 4$ & $81: 3-05: 4$ & $82: 3-05.4$ \\
\hline$\Delta$ GDP & 0.44 & 0.30 & 0.57 & 0.81 & 0.77 & 0.64 & 0.71 & 0.68 \\
$\pi$ & 0.00 & 0.07 & 0.04 & 0.00 & 0.02 & 0.01 & 0.41 & 0.50 \\
$\mathrm{R}$ & 0.38 & 0.09 & 0.02 & 0.08 & 0.01 & 0.00 & 0.02 & 0.01 \\
\hline \hline \multirow{2}{*}{ sample } & $60: 1-79: 2$ & $60: 1-80: 2$ & $60: 1-81: 2$ & $60: 1-82: 2$ & $79: 3-05: 4$ & $80: 3-05: 4$ & $81: 3-05: 4$ & $82: 3-05.4$ \\
\hline$\Delta$ GDPP & 0.25 & 0.28 & 0.10 & 0.18 & 0.10 & 0.19 & 0.11 & 0.14 \\
$\pi$ & 0.44 & 0.52 & 0.37 & 0.01 & 0.00 & 0.00 & 0.44 & 0.06 \\
$\mathrm{R}$ & 0.01 & 0.01 & 0.01 & 0.00 & 0.00 & 0.00 & 0.12 & 0.01 \\
\hline \hline
\end{tabular}

2 lags

\begin{tabular}{|c|c|c|c|c|c|c|c|c|}
\hline sample & 60:1-79:2 & $60: 1-80: 2$ & $\begin{array}{r}\text { Wit } \\
60: 1-81: 2\end{array}$ & $\begin{array}{l}\text { h Michiga } \\
60: 1-82: 2\end{array}$ & $\begin{array}{l}\text { in expecta } \\
79: 3-05: 4\end{array}$ & $\begin{array}{l}\text { ations } \\
80: 3-05: 4\end{array}$ & $81: 3-05: 4$ & $82: 3-05.4$ \\
\hline$\Delta \mathrm{GDP}$ & 0.49 & 0.35 & 0.76 & 0.85 & 0.96 & 0.67 & 0.90 & 0.49 \\
\hline$\pi$ & 0.01 & 0.08 & 0.01 & 0.00 & 0.00 & 0.00 & 0.36 & 0.49 \\
\hline $\mathrm{R}$ & 0.41 & 0.01 & 0.05 & 0.12 & 0.00 & 0.05 & 0.03 & 0.01 \\
\hline sample & $60: 1-79: 2$ & $60: 1-80: 2$ & $\begin{array}{r}\text { With T } \\
60: 1-81: 2\end{array}$ & $\begin{array}{l}\text { erm struc } \\
60: 1-82: 2\end{array}$ & $\begin{array}{l}\text { cture expe } \\
79: 3-05: 4\end{array}$ & $\begin{array}{l}\text { ectations } \\
80: 3-05: 4\end{array}$ & $|81: 3-05: 4|$ & $82: 3-05.4$ \\
\hline$\Delta \mathrm{GDP}$ & 0.31 & 0.26 & 0.09 & 0.22 & 0.15 & 0.24 & 0.08 & 0.12 \\
\hline$\pi$ & 0.50 & 0.51 & 0.45 & 0.02 & 0.00 & 0.00 & 0.37 & 0.04 \\
\hline $\mathrm{R}$ & 0.00 & 0.00 & 0.00 & 0.00 & 0.00 & 0.00 & 0.09 & 0.00 \\
\hline
\end{tabular}


3 lags

\begin{tabular}{|l|l|l|l|l|l|l|l|l|}
\hline \hline & \multicolumn{7}{|c|}{ With Michigan expectations } \\
sample & $60: 1-79: 2$ & $60: 1-80: 2$ & $60: 1-81: 2$ & $60: 1-82: 2$ & $79: 3-05: 4$ & $80: 3-05: 4$ & $81: 3-05: 4$ & $82: 3-05.4$ \\
\hline$\Delta$ GDP & 0.62 & 0.55 & 0.95 & 0.98 & 0.69 & 0.72 & 0.97 & 0.91 \\
$\pi$ & 0.60 & 0.08 & 0.00 & 0.00 & 0.00 & 0.00 & 0.10 & 0.08 \\
$\mathrm{R}$ & 0.16 & 0.07 & 0.20 & 0.18 & 0.00 & 0.01 & 0.05 & 0.02 \\
\hline \hline & \multicolumn{7}{|c|}{ With Term structure expectations } \\
sample & $60: 1-79: 2$ & $60: 1-80: 2$ & $60: 1-81: 2$ & $60: 1-82: 2$ & $79: 3-05: 4$ & $80: 3-05: 4$ & $81: 3-05: 4$ & $82: 3-05.4$ \\
\hline$\Delta$ GDP & 0.48 & 0.49 & 0.14 & 0.21 & 0.01 & 0.02 & 0.12 & 0.39 \\
$\pi$ & 0.52 & 0.50 & 0.16 & 0.00 & 0.00 & 0.00 & 0.72 & 0.27 \\
$\mathrm{R}$ & 0.00 & 0.00 & 0.00 & 0.00 & 0.00 & 0.00 & 0.05 & 0.00 \\
\hline \hline
\end{tabular}

8 lags

\begin{tabular}{|l|l|l|l|l|l|l|l|l|}
\hline \hline & \multicolumn{7}{|c|}{ With Michigan expectations } \\
sample & $60: 1-79: 2$ & $60: 1-80: 2$ & $60: 1-81: 2$ & $60: 1-82: 2$ & $79: 3-05: 4$ & $80: 3-05: 4$ & $81: 3-05: 4$ & $82: 3-05.4$ \\
\hline$\Delta$ GDP & 0.06 & 0.24 & 0.02 & 0.00 & 0.26 & 0.13 & 0.16 & 0.22 \\
$\pi$ & 0.00 & 0.03 & 0.01 & 0.02 & 0.02 & 0.00 & 0.00 & 0.01 \\
$\mathrm{R}$ & 0.11 & 0.10 & 0.53 & 0.42 & 0.01 & 0.06 & 0.18 & 0.05 \\
\hline \hline \multirow{7}{*}{ sample } & $60: 1-79: 2$ & $60: 1-80: 2$ & $60: 1-81: 2$ & $60: 1-82: 2$ & $79: 3-05: 4$ & $80: 3-05: 4$ & $81: 3-05: 4$ & $82: 3-05.4$ \\
\hline$\Delta$ GDP & 0.84 & 0.71 & 0.14 & 0.31 & 0.00 & 0.01 & 0.18 & 0.14 \\
$\pi$ & 0.10 & 0.04 & 0.13 & 0.25 & 0.00 & 0.01 & 0.67 & 0.34 \\
$\mathrm{R}$ & 0.44 & 0.00 & 0.00 & 0.00 & 0.00 & 0.00 & 0.01 & 0.03 \\
\hline \hline
\end{tabular}

The table reports the P-value for the F-test that expected inflation coefficients in the equation are all equal to zero in a VAR with 4 variables and varying lags. 
Table A.2: Variances of reduced form shocks

1 lags

\begin{tabular}{|l|l|l|l|l|l|l|l|l|}
\hline \hline & \multicolumn{7}{|c|}{ With Michigan expectations } \\
sample & $60: 1-79: 2$ & $60: 1-80: 2$ & $60: 1-81: 2$ & $60: 1-82: 2$ & $79: 3-05: 4$ & $80: 3-05: 4$ & $81: 3-05: 4$ & $82: 3-05.4$ \\
\hline$\Delta$ GDP & 1.12 & 1.11 & 1.21 & 1.39 & 0.79 & 0.69 & 0.67 & 0.52 \\
$\pi$ & 0.09 & 0.12 & 0.12 & 0.13 & 0.07 & 0.05 & 0.05 & 0.05 \\
R & 0.67 & 0.89 & 2.44 & 2.61 & 1.42 & 1.28 & 0.62 & 0.23 \\
\hline \hline & \multicolumn{7}{|c|}{ With Term structure expectations } \\
sample & $60: 1-79: 2$ & $60: 1-80: 2$ & $60: 1-81: 2$ & $60: 1-82: 2$ & $79: 3-05: 4$ & $80: 3-05: 4$ & $81: 3-05: 4$ & $82: 3-05.4$ \\
\hline$\Delta$ GDP & 1.12 & 1.07 & 1.14 & 1.33 & 0.77 & 0.69 & 0.62 & 0.48 \\
$\pi$ & 0.12 & 0.12 & 0.14 & 0.14 & 0.06 & 0.06 & 0.05 & 0.04 \\
R & 0.57 & 0.71 & 1.93 & 2.06 & 1.18 & 1.15 & 0.58 & 0.21 \\
\hline \hline \multirow{2}{*}{ sample } & $60: 1-79: 2$ & $60: 1-80: 2$ & $60: 1-81: 2$ & $60: 1-82: 2$ & $79: 3-05: 4$ & $80: 3-05: 4$ & $81: 3-05: 4$ & $82: 3-05.4$ \\
\hline$\Delta$ GDP & 1.15 & 1.14 & 1.28 & 1.21 & 0.81 & 0.71 & 0.67 & 0.53 \\
$\pi$ & 0.15 & 0.15 & 0.15 & 0.14 & 0.08 & 0.07 & 0.06 & 0.05 \\
$\mathrm{R}$ & 0.69 & 0.99 & 2.45 & 2.61 & 1.44 & 1.30 & 0.62 & 0.24 \\
\hline \hline
\end{tabular}

2 lags

\begin{tabular}{|l|l|l|l|l|l|l|l|l|l|}
\hline \hline & \multicolumn{7}{|c|}{ With Michigan expectations } \\
Sample & $60: 1-79: 2$ & $60: 1-80: 2$ & $60: 1-81: 2$ & $60: 1-82: 2$ & $79: 3-05: 4$ & $80: 3-05: 4$ & $81: 3-05: 4$ & $82: 3-05.4$ \\
\hline$\Delta$ GDP & 1.03 & 1.01 & 1.17 & 1.31 & 0.71 & 0.65 & 0.62 & 0.45 \\
$\pi$ & 0.08 & 0.10 & 0.11 & 0.11 & 0.05 & 0.04 & 0.04 & 0.04 \\
$\mathrm{R}$ & 0.62 & 0.86 & 2.03 & 2.33 & 1.24 & 1.22 & 0.51 & 0.18 \\
\hline \hline & \multicolumn{7}{|c|}{ With Term structure expectations } \\
sample & $60: 1-79: 2$ & $60: 1-80: 2$ & $60: 1-81: 2$ & $60: 1-82: 2$ & $79: 3-05: 4$ & $80: 3-05: 4$ & $81: 3-05: 4$ & $82: 3-05.4$ \\
\hline$\Delta$ GDP & 1.01 & 1.00 & 1.11 & 1.26 & 0.69 & 0.64 & 0.59 & 0.44 \\
$\pi$ & 0.10 & 0.11 & 0.12 & 0.12 & 0.05 & 0.05 & 0.04 & 0.03 \\
$\mathrm{R}$ & 0.52 & 0.64 & 1.78 & 1.99 & 1.09 & 1.11 & 0.52 & 0.18 \\
\hline \hline \multirow{2}{*}{ sample } & $60: 1-79: 2$ & $60: 1-80: 2$ & $60: 1-81: 2$ & $60: 1-82: 2$ & $79: 3-05: 4$ & $80: 3-05: 4$ & $81: 3-05: 4$ & $82: 3-05.4$ \\
\hline$\Delta$ GDP & 1.05 & 1.04 & 1.18 & 1.31 & 0.71 & 0.66 & 0.62 & 0.46 \\
$\pi$ & 0.10 & 0.11 & 0.11 & 0.11 & 0.06 & 0.06 & 0.04 & 0.04 \\
$\mathrm{R}$ & 0.63 & 0.97 & 2.15 & 2.46 & 1.38 & 1.30 & 0.55 & 0.20 \\
\hline \hline
\end{tabular}


3 lags

\begin{tabular}{|l|l|l|l|l|l|l|l|l|}
\hline \hline & \multicolumn{7}{|c|}{ With Michigan expectations } \\
sample & $60: 1-79: 2$ & $60: 1-80: 2$ & $60: 1-81: 2$ & $60: 1-82: 2$ & $79: 3-05: 4$ & $80: 3-05: 4$ & $81: 3-05: 4$ & $82: 3-05.4$ \\
\hline$\Delta$ GDP & 0.92 & 0.92 & 1.04 & 1.20 & 0.63 & 0.01 & 0.58 & 0.36 \\
$\pi$ & 0.08 & 0.10 & 0.10 & 0.10 & 0.05 & 0.04 & 0.03 & 0.03 \\
$\mathrm{R}$ & 0.54 & 0.81 & 1.62 & 1.99 & 0.96 & 0.95 & 0.48 & 0.16 \\
\hline \hline & With Term structure expectations \\
sample & $60: 1-79: 2$ & $60: 1-80: 2$ & $60: 1-81: 2$ & $60: 1-82: 2$ & $79: 3-05: 4$ & $80: 3-05: 4$ & $81: 3-05: 4$ & $82: 3-05.4$ \\
\hline$\Delta$ GDP & 0.91 & 0.92 & 0.97 & 1.13 & 0.57 & 0.56 & 0.54 & 0.35 \\
$\pi$ & 0.10 & 0.10 & 0.11 & 0.11 & 0.05 & 0.04 & 0.04 & 0.03 \\
$\mathrm{R}$ & 0.45 & 0.55 & 1.15 & 1.50 & 0.67 & 0.67 & 0.48 & 0.16 \\
\hline \hline & \multicolumn{7}{|c|}{ Without inflation expectations } \\
sample & $60: 1-79: 2$ & $60: 1-80: 2$ & $60: 1-81: 2$ & $60: 1-82: 2$ & $79: 3-05: 4$ & $80: 3-05: 4$ & $81: 3-05: 4$ & $82: 3-05.4$ \\
\hline$\Delta$ GDP & 0.95 & 0.95 & 1.05 & 1.20 & 0.64 & 0.61 & 0.98 & 0.95 \\
$\pi$ & 0.10 & 0.11 & 0.12 & 0.13 & 0.06 & 0.05 & 0.04 & 0.10 \\
$\mathrm{R}$ & 0.58 & 0.90 & 1.73 & 2.13 & 1.16 & 1.07 & 0.18 & 0.58 \\
\hline \hline
\end{tabular}

8 lags

\begin{tabular}{|l|l|l|l|l|l|l|l|l|}
\hline \hline & \multicolumn{7}{|c|}{ With Michigan expectations } \\
sample & $60: 1-79: 2$ & $60: 1-80: 2$ & $60: 1-81: 2$ & $60: 1-82: 2$ & $79: 3-05: 4$ & $80: 3-05: 4$ & $81: 3-05: 4$ & $82: 3-05.4$ \\
\hline$\Delta$ GDP & 0.43 & 0.52 & 0.51 & 0.53 & 0.31 & 0.27 & 0.23 & 0.21 \\
$\pi$ & 0.04 & 0.05 & 0.05 & 0.06 & 0.03 & 0.03 & 0.02 & 0.02 \\
$\mathrm{R}$ & 0.26 & 0.50 & 1.12 & 1.21 & 0.44 & 0.44 & 0.20 & 0.11 \\
\hline \hline & With Term structure expectations \\
sample & $60: 1-79: 2$ & $60: 1-80: 2$ & $60: 1-81: 2$ & $60: 1-82: 2$ & $79: 3-05: 4$ & $80: 3-05: 4$ & $81: 3-05: 4$ & $82: 3-05.4$ \\
\hline$\Delta$ GDP & 0.56 & 0.59 & 0.58 & 0.71 & 0.26 & 0.24 & 0.23 & 0.20 \\
$\pi$ & 0.05 & 0.05 & 0.06 & 0.07 & 0.03 & 0.03 & 0.02 & 0.02 \\
$\mathrm{R}$ & 0.30 & 0.41 & 0.72 & 0.79 & 0.36 & 0.35 & 0.18 & 0.11 \\
\hline \hline & Without inflation expectations \\
sample & $60: 1-79: 2$ & $60: 1-80: 2$ & $60: 1-81: 2$ & $60: 1-82: 2$ & $79: 3-05: 4$ & $80: 3-05: 4$ & $81: 3-05: 4$ & $82: 3-05.4$ \\
\hline$\Delta$ GDP & 0.63 & 0.67 & 0.75 & 0.85 & 0.36 & 0.32 & 0.27 & 0.25 \\
$\pi$ & 0.07 & 0.08 & 0.08 & 0.08 & 0.04 & 0.04 & 0.03 & 0.03 \\
$\mathrm{R}$ & 0.36 & 0.68 & 1.30 & 1.41 & 0.58 & 0.54 & 0.24 & 0.16 \\
\hline \hline
\end{tabular}


Table A.3: F-tests, p-values, Livingstone expectations

\begin{tabular}{|l|l|l|l|l|l|l|l|l|l|}
\hline \hline & \multicolumn{7}{|c|}{1 lag } \\
sample & $55: 1-79: 1$ & $55: 1-80: 1$ & $55: 1-81: 1$ & $55: 1-82: 1$ & $79: 2-06: 1$ & $80: 2-06: 1$ & $81: 2-06: 1$ & $81: 2-06.1$ \\
\hline$\Delta$ GDP & 0.59 & 0.77 & 0.68 & 0.63 & 0.29 & 0.88 & 0.77 & 0.51 \\
$\pi$ & 0.49 & 0.48 & 0.24 & 0.15 & 0.00 & 0.09 & 0.84 & 0.66 \\
$\mathrm{R}$ & 0.86 & 0.80 & 0.79 & 0.61 & 0.00 & 0.04 & 0.26 & 0.53 \\
\hline \hline & \multicolumn{7}{|c|}{2 lags } \\
sample & $55: 1-79: 1$ & $55: 1-80: 1$ & $55: 1-81: 1$ & $55: 1-82: 1$ & $79: 2-06: 1$ & $80: 2-06: 1$ & $81: 2-06: 1$ & $81: 2-06.1$ \\
\hline$\Delta$ GDP & 0.63 & 0.83 & 0.78 & 0.82 & 0.37 & 0.21 & 0.18 & 0.18 \\
$\pi$ & 0.67 & 0.51 & 0.42 & 0.43 & 0.01 & 0.20 & 0.09 & 0.31 \\
$\mathrm{R}$ & 0.60 & 0.83 & 0.90 & 0.91 & 0.20 & 0.06 & 0.08 & 0.30 \\
\hline \hline
\end{tabular}

The table reports the P-value for the F-test that expected inflation coefficients in the equation are all equal to zero in a VAR with 4 variables and varying lags.

Table A.4: Variances of reduced form shocks, Livingstone expectations

\begin{tabular}{|c|c|c|c|c|c|c|c|c|}
\hline & & & & & lags & & & \\
\hline sample & $55: 1-79: 1$ & $55: 1-80: 1$ & $|55: 1-81: 1|$ & $55: 1-82: 1$ & $1|79: 2-06: 1|$ & $80: 2-06: 1$ & $1|81: 2-06: 1|$ & $1 \mid 81: 2-06.1$ \\
\hline$\Delta \mathrm{GDP}$ & 1.21 & 1.42 & 1.47 & 1.47 & 0.83 & 0.81 & 0.81 & 0.72 \\
\hline$\pi$ & 0.27 & 0.27 & 0.31 & 0.33 & 0.11 & 0.10 & 0.09 & 0.09 \\
\hline $\mathrm{R}$ & 1.43 & 2.04 & 2.21 & 2.28 & 1.03 & 0.62 & 0.62 & 0.50 \\
\hline sample & $55: 1-7$ & $55: 1-8$ & $\mid 55: 1-8$ & $\begin{array}{r}21 \\
\mid 55: 1-82: 1\end{array}$ & $\begin{array}{l}\text { lags } \\
1 \mid 79: 2-06\end{array}$ & & & \\
\hline$\Delta$ GDP & \begin{tabular}{|l|}
0.80 \\
\end{tabular} & 1.13 & $\mid 1.18$ & 1.19 & 0.48 & \begin{tabular}{|l|}
$0.2-$ \\
0.36
\end{tabular} & 0.37 & $\begin{array}{l}101.2- \\
0.37\end{array}$ \\
\hline$\pi$ & 0.21 & 0.20 & 0.19 & 0.19 & 0.08 & 0.08 & 0.07 & 0.07 \\
\hline $\mathrm{R}$ & 1.12 & 1.75 & 1.86 & 2.03 & 0.81 & 0.47 & 0.46 & 0.40 \\
\hline & & & Witho & inflation & $\overline{\text { expecta }}$ & ons, 1 lags & & \\
\hline sample & $55: 1-79: 1$ & $55: 1-80: 1$ & $55: 1-8$ & $55: 1-82: 1$ & $1 \mid 79: 2-06$ & $80: 2-06: 1$ & $181: 2-0$ & $1 \mid 81: 2-06$ \\
\hline$\Delta \mathrm{GDP}$ & 1.26 & 1.44 & 1.51 & 1.50 & 0.88 & 0.81 & 0.82 & 0.72 \\
\hline$\pi$ & 0.28 & 0.28 & 0.33 & 0.33 & 0.16 & 0.11 & 0.09 & 0.09 \\
\hline $\mathrm{R}$ & 1.44 & 2.07 & 2.24 & 2.34 & 1.15 & 0.72 & 0.66 & 0.52 \\
\hline & & & Witho & inflatio & exnect. & ans? & & \\
\hline sample & $\mid 55: 1-79: 1$ & $55: 1-80: 1$ & $55: 1-81$ & $55: 1-82$ & $1 \mid 79: 2-06$ & $80: 2-06: 1$ & $1|81: 2-06: 1|$ & $1 \mid 81: 2-06$ \\
\hline$\Delta \mathrm{GDP}$ & 0.83 & 1.17 & 1.22 & 1.23 & 0.53 & 0.39 & 0.40 & 0.40 \\
\hline 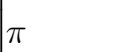 & 0.22 & 0.22 & 0.20 & 0.20 & 0.09 & 0.09 & 0.08 & 0.08 \\
\hline $\mathrm{R}$ & 1.15 & 1.79 & 1.90 & 2.08 & 0.84 & 0.49 & 0.49 & 0.43 \\
\hline
\end{tabular}


Table A.5: F-tests, p-values, Greenbook expectations

\begin{tabular}{|l|l|l|l|l|l|l|l|l|l|}
\hline \hline sample & $65: 4-79: 1$ & $65: 4-80: 1$ & $65: 4-81: 1$ & $65: 4-82: 1$ & $79: 2-01: 4$ & $80: 2-01: 4$ & $81: 2-01: 4$ & $81: 2-01.4$ \\
\hline$\Delta$ GDP & 0.54 & 0.25 & 0.01 & 0.00 & 0.82 & 0.10 & 0.21 & 0.10 \\
$\pi$ & 0.14 & 0.14 & 0.13 & 0.00 & 0.00 & 0.00 & 0.11 & 0.39 \\
R & 0.71 & 0.04 & 0.38 & 0.33 & 0.36 & 0.60 & 0.12 & 0.19 \\
\hline
\end{tabular}

The table reports the $\mathrm{P}$-value for the F-test that expected inflation coefficients in the equation are all equal to zero in a VAR with 4 variables and two lags.

Table A.6: Variances of reduced form shocks, Greenbook expectations

\begin{tabular}{|l|l|l|l|l|l|l|l|l|l|}
\hline \hline & \multicolumn{7}{|c|}{ With inflation expectations } \\
sample & $65: 4-79: 1$ & $65: 4-80: 1$ & $65: 4-81: 1$ & $65: 4-82: 1$ & $79: 2-01: 4$ & $80: 2-01: 4$ & $81: 2-01: 4$ & $81: 2-01.4$ \\
\hline$\Delta$ GDP & 0.87 & 0.84 & 0.96 & 1.11 & 0.79 & 0.68 & 0.66 & 0.47 \\
$\pi$ & 0.09 & 0.12 & 0.13 & 0.13 & 0.04 & 0.04 & 0.03 & 0.03 \\
$\mathrm{R}$ & 0.77 & 1.10 & 2.73 & 3.08 & 1.37 & 1.33 & 0.57 & 0.19 \\
\hline \hline & \multicolumn{7}{|c|}{ Without inflation expectations } \\
sample & $65: 4-79: 1$ & $65: 4-80: 1$ & $65: 4-81: 1$ & $65: 4-82: 1$ & $79: 2-01: 4$ & $80: 2-01: 4$ & $81: 2-01: 4$ & $81: 2-01.4$ \\
\hline$\Delta$ GDP & 1.00 & 1.00 & 1.21 & 1.38 & 0.79 & 0.73 & 0.69 & 0.51 \\
$\pi$ & 0.12 & 0.12 & 0.14 & 0.16 & 0.06 & 0.05 & 0.04 & 0.03 \\
$\mathrm{R}$ & 0.78 & 1.21 & 2.77 & 3.12 & 1.41 & 1.35 & 0.60 & 0.20 \\
\hline \hline
\end{tabular}


Table A.7: F-tests, p-values, Large system

\begin{tabular}{|l|l|l|l|l|l|l|l|l|}
\hline \hline sample & $60: 1-79: 2$ & $60: 1-80: 2$ & $60: 1-81: 2$ & $60: 1-82: 2$ & $79: 3-05: 4$ & $80: 3-05: 4$ & $81: 3-05: 4$ & $82: 3-05.4$ \\
\hline$\Delta$ GDP & 0.60 & 0.15 & 0.58 & 0.01 & 0.41 & 0.57 & 0.95 & 0.90 \\
$\pi$ & 0.94 & 0.90 & 0.96 & 0.71 & 0.95 & 0.90 & 0.97 & 0.96 \\
$\Delta$ C & 0.43 & 0.31 & 0.50 & 0.93 & 0.42 & 0.30 & 0.16 & 0.24 \\
$\Delta$ I & 0.18 & 0.14 & 0.26 & 0.11 & 0.14 & 0.16 & 0.06 & 0.04 \\
Hours & 0.91 & 0.88 & 0.75 & 0.78 & 0.29 & 0.22 & 0.35 & 0.30 \\
$\Delta$ M & 0.24 & 0.33 & 0.06 & 0.10 & 0.59 & 0.65 & 0.72 & 0.89 \\
$\mathrm{R}$ & 0.21 & 0.39 & 0.05 & 0.08 & 0.44 & 0.31 & 0.48 & 0.01 \\
\hline \hline sample & $60: 1-79: 2$ & $60: 1-80: 2$ & $60: 1-81: 2$ & $60: 1-82: 2$ & $79: 3-05: 4$ & $80: 3-05: 4$ & $81: 3-05: 4$ & $82: 3-05.4$ \\
\hline$\Delta$ GDP & 0.60 & 0.35 & 0.73 & 0.39 & 0.60 & 0.68 & 0.83 & 0.87 \\
$\pi$ & 0.74 & 0.84 & 0.43 & 0.84 & 0.96 & 0.68 & 0.38 & 0.50 \\
$\Delta$ C & 0.20 & 0.58 & 0.61 & 0.37 & 0.07 & 0.69 & 0.59 & 0.53 \\
$\Delta$ I & 0.33 & 0.41 & 0.25 & 0.73 & 0.38 & 0.03 & 0.19 & 0.16 \\
Hours & 0.92 & 0.57 & 0.97 & 0.99 & 0.60 & 0.52 & 0.59 & 0.64 \\
$\Delta$ M & 0.11 & 0.47 & 0.85 & 0.55 & 0.84 & 0.51 & 0.70 & 0.73 \\
$\mathrm{R}$ & 0.50 & 0.33 & 0.38 & 0.06 & 0.19 & 0.10 & 0.22 & 0.19 \\
\hline \hline
\end{tabular}

The table reports the P-value for the F-test that expected inflation coefficients in the equation are all equal to zero in a VAR with 8 variables and two lags. 
Table A.8: Variances of reduced form shocks, Large system

\begin{tabular}{|c|c|c|c|c|c|c|c|c|}
\hline & & & Witl & h Michiga & in expecta & ations & & \\
\hline sample & 55:1-79:1 & | $55: 1-80: 1$ & $155: 1-81: 1$ & $55: 1-82: 1$ & $79: 2-06: 1$ & | $80: 2-06: 1$ & $1|81: 2-06: 1|$ & $81: 2-06.1$ \\
\hline$\Delta \mathrm{GDP}$ & 1.06 & 1.14 & 1.20 & 1.32 & 0.60 & 0.58 & 0.44 & 0.45 \\
\hline$\pi$ & 0.30 & 0.30 & 0.30 & 0.32 & 0.31 & 0.30 & 0.31 & 0.29 \\
\hline$\Delta \mathrm{C}$ & 0.48 & 0.59 & 0.61 & 0.62 & .32 & 0.21 & 0.21 & 0.21 \\
\hline$\Delta \mathrm{I}$ & 9.09 & 10.2 & 11.0 & 10.6 & 5.04 & 4.07 & 2.95 & 2.91 \\
\hline Hours & 0.40 & 0.45 & 0.43 & 0.42 & 0.59 & 0.55 & 0.55 & 0.56 \\
\hline$\Delta \mathrm{M}$ & 362.3 & 371.8 & 371.7 & 370.8 & 142.6 & 135.1 & 118.9 & 112.2 \\
\hline $\mathrm{R}$ & 0.16 & 0.18 & 0.19 & 0.22 & 0.24 & 0.20 & 0.18 & 0.18 \\
\hline & & & $\begin{array}{r}\text { With T } \\
55 \cdot 1-81 \cdot 1\end{array}$ & erm s & ture ex & ectations & & \\
\hline sample & $55: 1-79$ & | $55: 1-80: 1$ & 1) 55:1-81:1 & $55: 1-\varepsilon$ & $79: 2-0$ & $80: 2-6$ & $181: 2-0$ & $81: 2-06.1$ \\
\hline$\Delta \mathrm{GDP}$ & 0.33 & 0.46 & 0.99 & 1.14 & 0.63 & 0.61 & 0.47 & 0.47 \\
\hline$\pi$ & 0.30 & 0.30 & 0.30 & 0.31 & 0.3 & 0.30 & 0.31 & 0.29 \\
\hline$\Delta \mathrm{C}$ & 0.59 & 0.38 & 0.44 & 0.60 & 0.39 & 0.21 & 0.21 & 0.21 \\
\hline$\Delta \mathrm{I}$ & 2.09 & 6.02 & 6.78 & 7.80 & 5.2 & 3.91 & 2.99 & 2.92 \\
\hline Hours & 0.22 & 0.3 & 0.44 & 0.42 & 0.5 & 0.55 & 0.54 & 0.56 \\
\hline$\Delta \mathrm{M}$ & 128.9 & 210.9 & 315.4 & 306.2 & 158.9 & 146.2 & 127.9 & 117.6 \\
\hline $\mathrm{R}$ & 0.10 & 0.18 & 0.25 & 0.25 & 0.23 & 0.18 & 0.17 & 0.16 \\
\hline & & & & jt & , & tations & & \\
\hline sample & $55: 1-79: 1$ & $55: 1-80: 1$ & $55: 1-81$ & $55: 1-82$ & & | $80: 2-06: 1$ & $181: 2-0$ & $81: 2-06$ \\
\hline$\Delta$ GDP & 1.08 & 1.21 & 1.22 & 1.49 & 0.61 & 0.59 & 0.45 & 0.45 \\
\hline$\pi$ & 0.30 & 0.30 & 0.30 & 0.32 & 0.31 & 0.30 & 0.31 & 0.30 \\
\hline$\Delta \mathrm{C}$ & 0.50 & 0.62 & 0.62 & 0.62 & 0.40 & 0.22 & 0.22 & 0.21 \\
\hline$\Delta \mathrm{I}$ & 9.63 & 10.8 & 11.5 & 11.3 & 5.26 & 4.25 & 3.16 & 3.16 \\
\hline Hours & 0.40 & 0.45 & 0.44 & 0.42 & 0.6 & 0.57 & 0.56 & 0.57 \\
\hline$\Delta \mathrm{M}$ & 380.3 & 385.3 & 403.7 & 395.8 & 144.3 & 136.5 & 119.8 & 112.5 \\
\hline $\mathrm{R}$ & 0.17 & 0.19 & 0.21 & 0.23 & 0.24 & 0.20 & 0.19 & 0.18 \\
\hline
\end{tabular}


Table A.9: F-tests, p-values, Using output growth expectations

\begin{tabular}{|c|c|c|c|c|c|c|c|c|}
\hline sample & $65: 4-79: 1$ & $\begin{array}{l}\text { Greenbo } \\
65: 4-80: 1\end{array}$ & $\begin{array}{c}\text { ook forecas } \\
\text { Lags } \\
1 \mid 65: 4-81: 1\end{array}$ & $\begin{array}{l}\text { sts, outpu } \\
\text { of inflatio } \\
65: 4-82: 1\end{array}$ & $\begin{array}{l}\text { it and infl } \\
\text { on expect } \\
\mid 79: 2-01: 4\end{array}$ & $\begin{array}{l}\text { flation exp } \\
\text { tations } \\
4 \mid 80: 2-01: 4\end{array}$ & $\begin{array}{l}\text { pectations } \\
4|81: 2-01: 4|\end{array}$ & $4 \mid 81: 2-01.4$ \\
\hline$\Delta \mathrm{GDP}$ & 0.57 & 0.26 & 0.02 & 0.00 & 0.28 & 0.05 & $\mid 0.21$ & 0.04 \\
\hline$\pi$ & 0.00 & 0.14 & 0.16 & 0.02 & 0.00 & 0.00 & 0.06 & 0.30 \\
\hline $\mathrm{R}$ & 0.32 & 0.06 & 0.33 & 0.24 & 0.59 & 0.98 & 0.15 & 0.09 \\
\hline sample & 65:4-79:1 65:4-80:1 $65: 4-81: 1|65: 4-82: 1| 79: 2-01: 4|80: 2-01: 4| 81: 2-01: 4 \mid 81: 2-01.4$ & \multicolumn{7}{|c|}{ Lags of output growth expectations } \\
\hline$\Delta \mathrm{GDP}$ & 0.58 & 0.71 & 0.28 & 0.06 & 0.02 & 0.18 & 0.24 & \begin{tabular}{|l|l|}
0.13 \\
\end{tabular} \\
\hline$\pi$ & 0.95 & 0.94 & 0.94 & 0.49 & 0.30 & 0.58 & 0.32 & 0.72 \\
\hline $\mathrm{R}$ & 0.58 & 0.82 & 0.17 & 0.03 & 0.04 & 0.03 & 0.69 & 0.16 \\
\hline sample & \multicolumn{8}{|c|}{ Greenbook forecasts, output expectations only } \\
\hline$\Delta \mathrm{GDP}$ & 0.55 & 0.72 & 0.29 & 0.11 & 0.06 & 0.33 & 0.24 & 0.29 \\
\hline$\pi$ & 0.96 & 0.91 & 0.93 & 0.20 & 0.47 & 0.58 & 0.54 & 0.95 \\
\hline $\mathrm{R}$ & 0.57 & 0.84 & 0.18 & 0.04 & 0.02 & 0.01 & 0.57 & 0.35 \\
\hline sample & \multicolumn{8}{|c|}{$\begin{array}{l}\text { Professional forecasts, output and inflation expectations } \\
\text { Lags of inflation expectations }\end{array}$} \\
\hline$\Delta$ GDP & 0.48 & 0.49 & 0.09 & 0.04 & 0.00 & 0.00 & 0.30 & 0.11 \\
\hline$\pi$ & 0.01 & 0.05 & 0.29 & 0.0 & 0.0 & 0.00 & 0.0 & 0.40 \\
\hline $\mathrm{R}$ & 0.40 & 0.64 & 0.53 & 0.49 & 0.00 & 0.00 & 0.00 & 0.00 \\
\hline sample & \multicolumn{8}{|c|}{ Lags of output growth expectations } \\
\hline$\Delta \mathrm{GDP}$ & 0.00 & 0.03 & 0.03 & 0.00 & 0.02 & 0.00 & 0.05 & 0.22 \\
\hline$\pi$ & 0.13 & 0.06 & 0.54 & 0.3 & 0.2 & 0.6 & 0.80 & 0.81 \\
\hline $\mathrm{R}$ & 0.77 & 0.19 & 0.60 & 0.34 & 0.02 & 0.03 & 0.06 & 0.71 \\
\hline sample & \multicolumn{8}{|c|}{ Professional forecasts, output expectations only } \\
\hline$\Delta \mathrm{GDP}$ & 0.00 & 0.01 & 0.04 & 0.01 & 0.10 & 0.03 & 0.17 & 0.33 \\
\hline$\pi$ & 0.20 & 0.10 & 0.48 & 0.1 & 0.02 & 0.31 & 0.76 & 0.65 \\
\hline $\mathrm{R}$ & 0.46 & 0.19 & 0.62 & 0.36 & 0.07 & 0.67 & 0.10 & 0.18 \\
\hline
\end{tabular}

The table reports the $\mathrm{P}$-value for the F-test that expected output coefficients in the equation are all equal to zero in a VAR with 4 variables and two lags. 
Table A.10: Variances of reduced form shocks, systems with output growth expectations

\begin{tabular}{|c|c|c|c|c|c|c|c|c|}
\hline sample & 65:4-79:1 & $\begin{array}{r}\text { Greenbo } \\
\text { 65:4-80:1 }\end{array}$ & ok foreca & $\begin{array}{l}\text { ists, outpu } \\
1 \mid 65: 4-82: 1\end{array}$ & it and infl & $\begin{array}{l}\text { Hation exp } \\
4 \mid 80: 2-01: 4\end{array}$ & $\begin{array}{l}\text { pectations } \\
4|81: 2-01: 4|\end{array}$ & $4 \mid 81: 2-01.4$ \\
\hline$\Delta \mathrm{GDP}$ & 0.85 & 0.83 & 0.92 & 1.00 & 0.71 & 0.65 & 0.64 & 0.45 \\
\hline$\pi$ & 0.09 & 0.12 & 0.13 & 0.13 & 0.04 & 0.04 & 0.03 & 0.03 \\
\hline $\mathrm{R}$ & 0.75 & 1.09 & 2.55 & 2.72 & 1.27 & 1.22 & 0.56 & 0.18 \\
\hline sample & 65:4-79 & $\begin{array}{r}\text { Gree } \\
65: 4-80: 1\end{array}$ & enbook fo & $\begin{array}{l}\text { recasts, o } \\
1 \mid 65: 4-82: 1\end{array}$ & $\begin{array}{l}\text { utput exp } \\
79: 2-01: 4\end{array}$ & $\begin{array}{l}\text { pectations } \\
4 \mid 80: 2-01: 4\end{array}$ & $\begin{array}{l}\text { sonly } \\
4|81: 2-01: 4|\end{array}$ & \\
\hline$\Delta \mathrm{GDP}$ & 0.87 & 1.21 & 1.07 & 1.22 & 0.74 & 0.71 & 0.67 & 0.49 \\
\hline$\pi$ & 0.12 & 0.14 & 0.14 & 0.15 & 0.06 & 0.05 & 0.04 & 0.03 \\
\hline $\mathrm{R}$ & 1.21 & 1.24 & 2.66 & 2.87 & 1.29 & 1.22 & 0.59 & 0.19 \\
\hline sample & $65: 4-79: 1$ & | 65:4-80:1 & |65:4-81:1 & $\begin{array}{l}\text { Withou } \\
\text { 1|65:4-8 }\end{array}$ & & $\begin{array}{l}n s \\
4 \mid 80: 2-0\end{array}$ & $4 \mid 81: 2-1$ & \\
\hline$\Delta \mathrm{GDP}$ & 1.00 & 1.00 & 1.21 & 1.38 & 0.79 & 0.73 & 0.69 & 0.51 \\
\hline$\pi$ & 0.12 & 0.12 & 0.14 & 0.1 & 0.0 & $0 .($ & 0.04 & 0.03 \\
\hline $\mathrm{R}$ & 0.78 & 1.21 & 2.77 & 3.12 & 1.41 & 1.35 & 0.60 & 0.20 \\
\hline sample & 68:1-79:1 & $\begin{array}{l}\text { Professio } \\
\mid 68: 1-80: 1\end{array}$ & $\begin{array}{l}\text { nal foreca } \\
\mid 68: 1-81: 1 \\
\end{array}$ & $\begin{array}{l}\text { asts, outp } \\
1 \mid 68: 1-82: 1\end{array}$ & $\begin{array}{l}\text { ut and inf } \\
79: 2-06: 1\end{array}$ & $\begin{array}{l}\text { flation exp } \\
1 \mid 80: 2-06: 1\end{array}$ & $\begin{array}{l}\text { pectations } \\
1 \mid 81: 2-06: 1\end{array}$ & $\begin{array}{l}\text { I } 181: 2-06 . \\
\end{array}$ \\
\hline$\Delta \mathrm{GDP}$ & 0.60 & 0.78 & 0.82 & 1.07 & 0.62 & 0.56 & $\mid 0.55$ & 0.44 \\
\hline$\pi$ & 0.09 & 0.09 & 0.13 & 0.1 & 0.0 & $0 .($ & 0.0 & 0.04 \\
\hline $\mathrm{R}$ & 0.84 & 1.01 & 3.14 & 3.17 & 1.15 & 1.12 & 0.46 & 0.27 \\
\hline sample & $68: 1-79: 1$ & $\begin{array}{r}\text { Profe } \\
168: 1-80: 1\end{array}$ & essional fo & $\begin{array}{l}\text { orecasts, } \\
1 \mid 68: 1-82: 1\end{array}$ & $\begin{array}{l}\text { Dutput } \\
79: 2-06\end{array}$ & $1 \mid 80: 2-06: 1$ & $\begin{array}{l}\text { s only } \\
1 \mid 81: 2-06: 1\end{array}$ & \\
\hline$\Delta \mathrm{GDP}$ & 0.63 & 0.81 & 0.93 & 1.24 & 0.74 & 0.6 & 0.65 & 0.46 \\
\hline$\pi$ & 0.12 & 0.11 & 0.13 & 0.16 & 0.0 & 0.0 & 0.04 & 0.04 \\
\hline $\mathrm{R}$ & 0.89 & 1.04 & 3.25 & 3.27 & 1.33 & 1.31 & 0.53 & 0.30 \\
\hline sample & $68: 1-79$ & |68:1-80:1 & 68:1-81 & $\begin{array}{l}\text { Without } \\
1 \mid 68: 1-8\end{array}$ & $\begin{array}{l}\text { xpecta } \\
\mid 79: 2-0\end{array}$ & $\begin{array}{l}\text { nns } \\
1 \mid 80: 2-0\end{array}$ & $1 \mid 81: 2-06$ & \\
\hline$\Delta$ GDP & 0.94 & 0.97 & 1.13 & 1.43 & 0.78 & 0.71 & 0.67 & 0.48 \\
\hline$\pi$ & 0.13 & 0.12 & 0.14 & 0.17 & 0.0 & 0.0 & 0.04 & 0.04 \\
\hline $\mathrm{R}$ & 0.90 & 1.09 & 3.23 & 3.33 & 1.40 & 1.38 & 0.56 & 0.31 \\
\hline
\end{tabular}

The table reports the $\mathrm{P}$-value for the F-test that expected output coefficients in the equation are all equal to zero in a VAR with 4 variables and two lags. 
Table A.11: F-tests, p-values, Simulated data

\begin{tabular}{|c|c|c|c|c|c|c|c|c|}
\hline \multirow{2}{*}{ sample } & \multicolumn{8}{|c|}{$\begin{array}{l}\text { Continuity Solution } \\
\end{array}$} \\
\hline & 0.06 & 0.04 & 0.44 & 0.90 & 0.60 & 0.47 & 0.70 & 0.65 \\
\hline$\pi$ & 0.08 & 0.08 & 0.39 & 0.57 & 0.52 & 0.51 & 0.49 & 0.40 \\
\hline $\mathrm{R}$ & 0.53 & 0.54 & 0.82 & 0.22 & 0.99 & 0.99 & 0.93 & 0.93 \\
\hline sample & $60: 1-7$ & $460: 1-7$ & $460: 1-$ & $\begin{array}{l}\text { Orthoge } \\
4 \mid 60: 1-\end{array}$ & $\begin{array}{l}\text { lity So } \\
\text { 4 } 79: 1-9\end{array}$ & $\begin{array}{l}\text { tion } \\
: 4 \mid 80: 1-\end{array}$ & $481: 1-$ & \begin{tabular}{l|l|}
4 & $82: 1-99.4$ \\
\end{tabular} \\
\hline$\Delta \mathrm{GDP}$ & 0.04 & 0.04 & 0.08 & 0.22 & 0.60 & 0.60 & 0.70 & 0.65 \\
\hline$\pi$ & 0.00 & 0.00 & 0.12 & 0.81 & 0.36 & 0.39 & 0.49 & 0.40 \\
\hline $\mathrm{R}$ & 0.90 & 0.90 & 0.71 & 0.44 & 0.84 & 0.82 & 0.93 & 0.93 \\
\hline
\end{tabular}

The table reports the $\mathrm{P}$-value for the F-test that expected inflation coefficients in the equation are all equal to zero in a VAR with 4 variables and two lags. Data from 1960:1 to 1979:4 are generated from the indeterminate solution, data from 1980:1 to 1999:4 are generated from the determiante solution.

Table A.12: Variances of reduced form shocks, Simulated data

\begin{tabular}{|c|c|c|c|c|c|c|c|c|}
\hline sample & $60: 1-78: 4$ & $60: 1-79: 4$ & $60: 1-80: 4$ & $\begin{array}{l}\text { Continuity } \\
60: 1-81: 4\end{array}$ & $\begin{array}{l}y \text { solution } \\
\mid 79: 1-99: 4\end{array}$ & $80: 1-99: 4$ & | $81: 1-99: 4$ & $82: 1-99.4$ \\
\hline$\Delta \mathrm{GDP}$ & 3.32 & 3.22 & 3.27 & 3.26 & $\mid 1.05$ & 0.99 & 0.96 & 0.89 \\
\hline$\pi$ & 1.63 & 1.58 & 1.56 & 1.54 & 0.38 & 0.36 & 0.37 & 0.34 \\
\hline $\mathrm{R}$ & 0.87 & 0.84 & 0.83 & 0.89 & 1.07 & 1.11 & 1.16 & 1.09 \\
\hline sample & 60:1-78:4 & $60: 1-79: 4$ & $60: 1-80: 4$ & $\begin{array}{l}\text { rthogonali } \\
60: 1-81: 4\end{array}$ & $\begin{array}{l}\text { lity Solutic } \\
79: 1-99: 4\end{array}$ & $\begin{array}{l}\text { on } \\
80: 1-99: 4\end{array}$ & |81:1-99:4 & $82: 1-99.4$ \\
\hline$\Delta \mathrm{GDP}$ & 1.01 & 1.02 & 1.04 & 1.15 & 0.99 & 0.93 & 0.96 & 0.89 \\
\hline$\pi$ & 0.16 & 0.16 & 0.19 & 0.25 & 0.37 & 0.36 & 0.37 & 0.34 \\
\hline $\mathrm{R}$ & 0.08 & 0.08 & 0.08 & 0.17 & 1.08 & 1.12 & 1.16 & 1.09 \\
\hline sample & $55: 1-79: 1$ & $\begin{array}{r}\text { Withou } \\
\mid 55: 1-80: 1\end{array}$ & $\begin{array}{l}\text { ut inflation } \\
\mid 55: 1-81: 1\end{array}$ & $\begin{array}{l}\text { n expecta } \\
|55: 1-82: 1|\end{array}$ & $\begin{array}{l}\text { ations, Cor } \\
|79: 2-06: 1|\end{array}$ & $\begin{array}{l}\text { ntinuity s } \\
80: 2-06: 1 \mid\end{array}$ & $\begin{array}{l}\text { solution } \\
\mid 81: 2-06: 1\end{array}$ & $81: 2-06.1$ \\
\hline$\Delta \mathrm{GDP}$ & 3.48 & 3.40 & 3.29 & 3.26 & 1.05 & \begin{tabular}{|l|}
0.99 \\
\end{tabular} & 0.96 & 0.89 \\
\hline$\pi$ & 1.68 & 1.63 & 1.56 & 1.54 & 0.38 & 0.36 & 0.37 & 0.35 \\
\hline $\mathrm{R}$ & 0.88 & 0.88 & 0.83 & 0.90 & 1.08 & 1.11 & 1.09 & 1.10 \\
\hline sample & $55: 1-79: 1$ & $\begin{array}{l}\text { Without } \\
55: 1-80: 1\end{array}$ & $\begin{array}{l}\text { inflation } \\
55: 1-81: 1\end{array}$ & $\begin{array}{l}\text { expectati } \\
55: 1-82: 1\end{array}$ & $\begin{array}{l}\text { ions, Orth } \\
79: 2-06: 1\end{array}$ & $\begin{array}{l}\text { ogonality } \\
80: 2-06: 1 \mid\end{array}$ & $\begin{array}{l}\text { y solution } \\
\mid 81: 2-06: 1 \\
\end{array}$ & $81: 2-06.1$ \\
\hline$\Delta \mathrm{GDP}$ & 1.04 & 1.04 & 1.06 & 1.12 & 0.98 & 0.87 & 0.93 & 0.84 \\
\hline$\pi$ & 0.18 & 0.19 & 0.19 & 0.24 & 0.35 & 0.34 & 0.34 & 0.32 \\
\hline $\mathrm{R}$ & 0.09 & 0.09 & 0.08 & 0.17 & 1.00 & 1.04 & 1.08 & 1.04 \\
\hline
\end{tabular}


Table A.13: F-tests, p-values, Simulated data with measurement error

\begin{tabular}{|l|l|l|l|l|l|l|l|l|l|}
\hline \hline \multirow{2}{*}{ sample } & $60: 1-78: 4$ & $60: 1-79: 4$ & $60: 1-80: 4$ & $60: 1-81: 4$ & $79: 1-99: 4$ & $80: 1-99: 4$ & $81: 1-99: 4$ & $82: 1-99.4$ \\
\hline$\Delta$ GDP & 0.00 & 0.00 & 0.05 & 0.07 & 0.16 & 0.10 & 0.92 & 0.70 \\
$\pi$ & 0.14 & 0.17 & 0.23 & 0.94 & 0.16 & 0.20 & 0.26 & 0.32 \\
$\mathrm{R}$ & 0.05 & 0.05 & 0.10 & 0.17 & 0.10 & 0.10 & 0.25 & 0.26 \\
\hline \hline \multirow{8}{*}{ sample } & $60: 1-78: 4$ & $60: 1-79: 4$ & $60: 1-80: 4$ & $60: 1-81: 4$ & $79: 1-99: 4$ & $80: 1-99: 4$ & $81: 1-99: 4$ & $82: 1-99.4$ \\
\hline$\Delta$ GDP & 0.05 & 0.05 & 0.10 & 0.34 & 0.74 & 0.30 & 0.92 & 0.70 \\
$\pi$ & 0.36 & 0.28 & 0.60 & 0.05 & 0.23 & 0.25 & 0.26 & 0.32 \\
$\mathrm{R}$ & 0.61 & 0.63 & 0.82 & 0.68 & 0.10 & 0.15 & 0.25 & 0.26 \\
\hline \hline \multirow{2}{*}{ sample } & $60: 1-78: 4$ & $60: 1-79: 4$ & $60: 1-80: 4$ & $60: 1-81: 4$ & $79: 1-99: 4$ & $80: 1-99: 4$ & $81: 1-99: 4$ & $82: 1-99.4$ \\
\hline$\Delta$ GDP & 0.00 & 0.00 & 0.04 & 0.07 & 0.16 & 0.10 & 0.92 & 0.70 \\
$\pi$ & 0.12 & 0.14 & 0.21 & 0.90 & 0.16 & 0.20 & 0.26 & 0.32 \\
$\mathrm{R}$ & 0.04 & 0.05 & 0.09 & 0.15 & 0.10 & 0.10 & 0.25 & 0.26 \\
\hline \hline
\end{tabular}

The table reports the $\mathrm{P}$-value for the F-test that expected inflation coefficients in the equation are all equal to zero in a VAR with 4 variables and two lags. Data from 1960:1 to 1979:4 are generated from the indeterminate solution, data from 1980:1 to 1999:4 are generated from the determinate solution. When measurement error is serially correlated, the persistence coefficent is set to 0.9.

Table A.14: Variances of reduced form shocks, Simulated data with measurement error

\begin{tabular}{|c|c|c|c|c|c|c|c|c|}
\hline sample & $60: 1-78: 4$ & $60: 1-79: 4$ & $\begin{array}{r}\text { Conti } \\
60: 1-80: 4\end{array}$ & $\begin{array}{l}\text { inuity solu } \\
\mid 60: 1-81: 4\end{array}$ & $\begin{array}{l}\text { Iution, iid } \\
4 \mid 79: 1-99: 4\end{array}$ & $\begin{array}{l}\text { errors } \\
4 \mid 80: 1-99: 4\end{array}$ & $81: 1-99: 4$ & $82: 1-99.4$ \\
\hline$\Delta \mathrm{GDP}$ & 3.47 & 3.42 & 3.41 & 3.31 & 0.18 & 0.07 & 0.05 & 0.05 \\
\hline$\pi$ & 1.67 & 1.66 & 1.72 & 1.70 & 1.65 & 1.64 & 1.62 & 1.70 \\
\hline $\mathrm{R}$ & 1.41 & 1.41 & 1.40 & 1.36 & 0.18 & 0.12 & 0.11 & 0.12 \\
\hline sample & $60: 1-78: 4$ & $60: 1-79: 4$ & $\begin{array}{r}\text { Orthog } \\
60: 1-80: 4\end{array}$ & $\begin{array}{l}\text { sonality Sc } \\
\mid 60: 1-81: 4\end{array}$ & $\begin{array}{l}\text { olution, ii } \\
4 \mid 79: 1-99: 4\end{array}$ & $\begin{array}{l}\text { id errors } \\
4 \mid 80: 1-99: 4\end{array}$ & $81: 1-99: 4$ & $82: 1-99.4$ \\
\hline$\Delta \mathrm{GDP}$ & 1.38 & 1.40 & 1.72 & 1.69 & 0.50 & 0.13 & 0.05 & 0.05 \\
\hline$\pi$ & 0.19 & 0.19 & 0.29 & 0.30 & 1.57 & 1.64 & 1.62 & 1.70 \\
\hline $\mathrm{R}$ & 0.52 & 0.52 & 0.56 & 0.53 & 0.15 & 0.12 & 0.11 & 0.12 \\
\hline sample & $\begin{array}{r}\mathrm{Wi} \\
55: 1-79: 1 \\
\end{array}$ & $\begin{array}{l}\text { ithout inf } \\
55: 1-80: 1 \\
\end{array}$ & $\begin{array}{l}\text { lation exp } \\
55: 1-81: 1\end{array}$ & $\begin{array}{l} \\
55: 1-82: 1\end{array}$ & $\begin{array}{l}\text { s, Continu } \\
1 \mid 79: 2-06: 1\end{array}$ & $\begin{array}{l}\text { uity solutic } \\
1 \mid 80: 2-06: 1\end{array}$ & $\begin{array}{l}\text { on, iid err } \\
81: 2-06: 1\end{array}$ & $\begin{array}{l}\text { rors } \\
81: 2-06.1\end{array}$ \\
\hline$\Delta \mathrm{GDP}$ & 3.82 & 3.74 & 3.58 & 3.44 & 0.19 & 0.08 & 0.05 & 0.05 \\
\hline$\pi$ & 1.72 & 1.71 & 1.76 & 1.70 & 1.69 & 1.68 & 1.65 & 1.73 \\
\hline $\mathrm{R}$ & 1.49 & 1.48 & 1.45 & 1.39 & 0.18 & 0.13 & 0.12 & 0.12 \\
\hline sample & $\begin{array}{r}\text { Witl } \\
55: 1-79: 1 \\
\end{array}$ & $\begin{array}{l}\text { hout infla } \\
55: 1-80: 1\end{array}$ & $\begin{array}{l}\text { tion expec } \\
55: 1-81: 1\end{array}$ & $\begin{array}{l}\text { ctations, } \\
55: 1-82: 1\end{array}$ & $\begin{array}{r}\text { Orthogon } \\
1 \mid 79: 2-06: 1\end{array}$ & $\begin{array}{l}\text { hality solut } \\
1 \mid 80: 2-06: 1\end{array}$ & $\begin{array}{l}\text { tion, iid en } \\
\mid 81: 2-06: 1\end{array}$ & $\begin{array}{l}\text { errors } \\
81: 2-06.1\end{array}$ \\
\hline$\Delta \mathrm{GDP}$ & 1.35 & 1.37 & 1.66 & 1.61 & 0.47 & 0.12 & 0.05 & 0.05 \\
\hline$\pi$ & 0.18 & 0.18 & 0.29 & 0.27 & 1.57 & 1.64 & 1.61 & 1.67 \\
\hline $\mathrm{R}$ & 0.53 & 0.52 & 0.56 & 0.54 & 0.15 & 0.11 & 0.11 & 0.11 \\
\hline
\end{tabular}

